\title{
Central tolerance is impaired in the middle-aged thymic environment
}

Jessica N. Lancaster ${ }^{1,4 \dagger}$, Damaris L. Keatinge-Clay ${ }^{1 \dagger}$, Jayashree Srinivasan ${ }^{1}, \mathrm{Yu} \mathrm{Li}^{1}$, Hilary J. Selden ${ }^{1}$, Seohee Nam ${ }^{1}$, Ellen R. Richie ${ }^{2}$, Lauren I. R. Ehrlich ${ }^{1,3 *}$

1 The University of Texas at Austin, Department of Molecular Biosciences, Austin, TX

2 The University of Texas MD Anderson Cancer Center, Department of Epigenetics and Molecular Carcinogenesis, Houston, TX

${ }^{3}$ Dell Medical School at The University of Texas at Austin, Department of Oncology, Austin, TX

${ }^{4}$ current address: The Mayo Clinic, Department of Immunology, Scottsdale, AZ

${ }^{\dagger}$ co-first authors with equal contributions

* corresponding author: Lauren I.R. Ehrlich lehrlich@austin.utexas.edu 


\section{Summary}

One of the earliest hallmarks of immune aging is thymus involution, which not only reduces the number of newly generated and exported $T$ cells, but also alters the composition and organization of the thymic microenvironment. Thymic T-cell export continues into adulthood, yet the impact of thymic involution on the quality of newly generated T-cell clones is not well established. Notably, the number and proportion of medullary thymic epithelial cells (mTECs) and expression of tissue restricted antigens (TRAs) decline with age, suggesting the involuting thymus may not promote efficient central tolerance. Here, we demonstrate that the middle-aged thymic environment does not support rapid motility of medullary thymocytes, potentially diminishing their ability to scan antigen presenting cells that display the diverse self-antigens that induce central tolerance. Consistent with this possibility, thymic slice assays reveal that the middle-aged thymic environment does not support efficient negative selection or regulatory $\mathrm{T}$ cell (Treg) induction of thymocytes responsive to either TRAs or ubiquitous self-antigens. This decline in central tolerance is not universal, but instead impacts lower-avidity selfantigens that are either presented at low levels or bind to TCRs with moderate affinities. Additionally, the decline in thymic tolerance by middle-age is accompanied by both a reduction in mTECs and hematopoietic antigen presenting cell subsets that cooperate to drive central tolerance. Thus, age-associated changes in the thymic environment result in impaired central tolerance against moderate avidity self-antigens, potentially resulting in export of increasingly autoreactive naive $T$ cells, with a deficit of Treg counterparts by middle age. 


\section{Introduction}

Thymus involution begins in childhood, resulting in a progressive reduction in the generation and export of naive T cells with age (Chinn et al. 2012). Diminished thymic output contributes to the age-associated decline in T-cell immunity, one of the major drivers of immune dysfunction in aged mice and humans (Elyahu \& Monsonego 2021; Nikolich-Žugich 2014). However, the thymus continues to produce and export new T cells, albeit at reduced numbers, into advanced age (Hale et al. 2006; Lynch et al. 2009; Flores et al. 1999). In fact, measurement of human T-cell receptor excision circles (TRECs) indicates that thymic output is detectable until $\sim 80$ years of age (Mitchell et al. 2010; Nasi et al. 2006). Although mature naïve $T$ cells in humans are largely maintained by homeostatic proliferation (Mold et al. 2019), thymic output is required to sustain a normal number of naive T cells in both mice and humans (Appay \& Sauce 2014; Bourgeois et al. 2008). Moreover, the thymus remains the sole source of new conventional T-cell and Treg clones throughout life, yet little is known about the impact of thymus aging on qualitative changes in T-cell maturation and selection.

As the thymus involutes and fewer recent thymic emigrants are exported, the peripheral T compartment is progressively comprised of cells with a memory phenotype (Nikolich-Žugich 2008; Srinivasan et al. 2021; Goronzy \& Weyand 2019). This reduction in naïve T cells in the elderly contributes to increased susceptibility to infectious disease and decreased responsiveness to vaccines (Nikolich-Žugich 2014). Interestingly, while the number of new $T$ cells exported from the thymus declines substantially by middle-age (Mold et al. 2019; den Braber et al. 2012; Ito et al. 2017), the incidence of new-onset autoimmunity peaks at middle-age for many autoimmune disorders (Watad et al. 2017). 
Both naive CD4 ${ }^{+}$and CD8 ${ }^{+}$T cells (Quinn et al. 2016; Rudd et al. 2011; Deshpande et al. 2015) become more self-reactive with age in mice, suggesting that changes in thymic selection could contribute to increased T-cell auto-reactivity with age.

The thymic medulla is a specialized microenvironment for inducing T-cell central tolerance to diverse autoantigens. Following T-lineage commitment, differentiation, and positive selection in the thymic cortex, developing $T$ cells express chemokine receptors that promote their entry into the medulla (Cowan et al. 2014; Kadakia et al. 2019; Kurobe et al. 2006; Lancaster et al. 2018; Ehrlich et al. 2009; Hu et al. 2015), where they encounter numerous self-antigens presented by medullary thymic epithelial cells (mTECs) and hematopoietic antigen presenting cells (HAPCs), including conventional dendritic cells (cDCs), B cells, and plasmacytoid dendritic cells (pDCs). If a thymocyte expresses a T-cell receptor (TCR) with sufficiently high affinity for these self-antigens, it undergoes negative selection or diversion to the Treg lineage, enforcing central tolerance (Klein et al. 2014). Mature mTECs play an essential role in tolerance induction, as they collectively express about $90 \%$ of the proteome, including Aire-dependent tissuerestricted antigens (TRAs), which are otherwise expressed in only a few peripheral tissues (Bautista et al. 2021; Bornstein et al. 2018; Brennecke et al. 2015; Meredith et al. 2015; Sansom et al. 2014). It is critical that thymocytes are tolerized to the full repertoire of mTEC-derived self-antigens to avoid autoimmunity (Aaltonen et al. 1997; Anderson 2002; DeVoss et al. 2006; Nagamine et al. 1997), but a given TRA is expressed by only -1-3\% of mTECs (Derbinski et al. 2005; Derbinski et al. 2008), creating a sparse mosaic of self-antigen display in the medulla. Thymic cDCs also play a critical role in thymic tolerance by presenting self-antigens acquired from circulation, peripheral tissues, and 
mTECs (Bonasio et al. 2006; Atibalentja et al. 2011; Perry et al. 2014, 2018; Leventhal et al. 2016; Watanabe et al. 2020; Vollmann et al. 2021). Thus, it is critical that post-positive selection thymocytes enter the medulla efficiently and rapidly scan mTECs and HAPCs to encounter the complete arrays of self-antigens needed to induce broad central tolerance.

Age-associated changes in thymic APCs and self-antigen expression could impair the ability of the thymus to support central tolerance. Aging is associated with substantial changes in thymic stromal organization and composition (Baran-Gale et al. 2020; Chinn et al. 2012; Lynch et al. 2009; Srinivasan et al. 2021; Venables et al. 2019). In the aged thymus, the cortex thins (Venables et al. 2019), TEC proliferation and cellularity is greatly reduced (Gray et al. 2006), and the frequency and number of mTECs decline (Chinn et al. 2012; Lepletier et al. 2019; Baran-Gale et al. 2020). Notably, expression of TRAs in the medulla diminishes with age (Griffith et al. 2012), and thymic B cells and DCs change in composition and molecular properties (Cepeda et al. 2018; Flores et al. 2001; Nuñez et al. 2016; Ki et al. 2014; van Dommelen et al. 2010; Varas et al. 2003).

The efficiency with which auto-reactive thymocytes are negatively selected is dependent on the TCR-binding avidity of the selecting self-antigen. High avidity selfantigens induce efficient negative selection (Klein et al. 2019), while thymocytes expressing TCRs that bind self-antigen with moderate avidity can escape negative selection, resulting in autoimmune pathology (Koehli et al. 2014; Zehn \& Bevan 2006). Beyond TCR binding affinity, the pattern of self-antigen expression in the thymus also modulates autoreactive thymocyte fates. Ubiquitously-expressed self-antigens tend to induce more robust negative selection, while rare, Aire-dependent TRAs induce both 
negative selection and Treg induction (Malhotra et al. 2016; Hassler et al. 2019). Given that aging results in diminished expression of TRAs and changes in the composition and organization of mTECs and HAPCs, autoreactive thymocytes in the aged microenvironment may be screened less efficiently against ubiquitous and/or rare, tissuespecific self-antigens. However, little is known about the impact of aging on thymocyte selection. In a genetically-induced mouse model of accelerated thymic involution, negative selection was impaired, but Treg induction was enhanced (Coder et al. 2015; Oh et al. 2017). In contrast, following natural aging, generation of new thymic Tregs diminished (Thiault et al. 2015), which was attributed to an increase in peripheral Treg reentering the thymus and outcompeting resident Treg progenitors for IL-2 (Hemmers et al. 2019; Weist et al. 2015). These findings raise questions about whether the aged thymus supports efficient negative selection and Treg induction against different types of selfantigens.

In this study, we use live thymic slices in combination with 2-photon microscopy (2PM) to test the ability of the naturally aged thymic environment to support thymocyte medullary entry and rapid motility, as well as negative selection and Treg induction in response to ubiquitous self-antigens or model TRAs. We find that thymocytes, regardless of age, do not migrate as rapidly in a middle-aged 12-month $(\mathrm{MO})$ relative to a $1 \mathrm{MO}$ thymic environment. Furthermore, the middle-aged thymus does not support efficient negative selection or Treg induction of thymocytes responsive to self-antigens of moderate avidities. However, central tolerance, including Treg induction, remains intact for thymocytes responsive to ubiquitous high-affinity self-antigens in the middle-aged thymus. Thus, the middle-aged thymus does not support efficient central tolerance to moderate- 
avidity self-antigens, possibly resulting in export of poorly tolerized T cells to the periphery by middle-age.

\section{Results}

The middle-aged thymus environment does not support rapid motility of medullary thymocytes

To test whether the middle-aged thymic environment supports rapid motility and efficient accumulation of post-positive selection thymocytes in the medulla, we used 2PM to image young $1 \mathrm{MO}$ and middle-aged $12 \mathrm{MO}$ polyclonal mouse $\mathrm{CD}^{+}$single-positive (CD4SP) thymocytes migrating in either $1 \mathrm{MO}$ or $12 \mathrm{MO}$ live thymic slices (Figure 1a). We first determined that expression of CCR4 and CCR7, which promote medullary entry (Ehrlich et al. 2009; Hu et al. 2015; Ueno et al. 2004), are comparable between $1 \mathrm{MO}$ and $12 \mathrm{MO}$ thymocytes (Supplementary Figure 1a). Next, CD4SPs from $1 \mathrm{MO}$ and 12MO thymuses were labeled with red or blue fluorescent dyes and allowed to migrate in $1 \mathrm{MO}$ versus $12 \mathrm{MO}$ thymic slices generated from $\mathrm{pCX}$-EGFP mice, in which cortical and medullary regions can be distinguished by cellular morphology and EGFP intensity (Lancaster \& Ehrlich 2017). Thymocyte migration was imaged by time-lapse 2PM, and cells were tracked to determine their density in the medulla and cortex, as well their velocity and path straightness (Figure 1b and Supplementary Movies 1-2).

The ratio of CD4SPs within the medulla relative to the cortex declined in the $12 \mathrm{MO}$ versus $1 \mathrm{MO}$ thymic environment, irrespective of thymocyte age (Figure 1c). However, the density of CD4SP cells in the medulla of $12 \mathrm{MO}$ thymuses was not significantly reduced (Figure 1d); instead, the density of CD4SP cells in the 12MO cortex increased, 
likely reflecting age-associated cortical thinning (Venables et al. 2019; Chinn et al. 2012)

(Figure 1e). Consistent with robust accumulation of CD4SP in the12MO medulla, expression of CCL21, the CCR7 ligand required for accumulation of CD4SP thymocytes in the medulla (Kozai et al. 2017), was elevated in the $12 \mathrm{MO}$ versus $1 \mathrm{MO}$ medulla (Supplementary Figure 1b). Notably, CD4SPs of both ages migrated significantly more slowly in the $12 \mathrm{MO}$ versus $1 \mathrm{MO}$ thymus (Figure 1f). Neither the age of the thymocytes nor the thymic environment significantly impacted the straightness of thymocyte migration paths (Figure 19). Thus, the middle-aged thymus environment supports robust entry of CD4SP cells into the medulla but does not support their rapid migration, both of which enable efficient scanning of self-antigens presented by medullary APCs.

\section{Thymic slice deletion assays for quantification of age-associated changes in central tolerance}

We next investigated whether central tolerance induction is impaired in the middleaged thymic environment using live thymic slice deletion assays. Negative selection of young $1 \mathrm{MO}$ CD8SP or CD4SP thymocytes responding to self-antigens in $1 \mathrm{MO}$ versus $12 \mathrm{MO}$ thymic slices was quantified by flow cytometry (Figure 2a) (Hu et al. 2015; Lancaster et al. 2019). TCR transgenic thymocytes specific for ovalbumin peptides (OVAp) were mixed at an equal ratio with polyclonal CD45-congenic thymocytes prior to loading onto $1 \mathrm{MO}$ or $12 \mathrm{MO}$ thymic slices. The polyclonal thymocytes served as nonselecting controls to normalize for differential cell entry into individual slices. To assay for negative selection, the slices 1) lacked ovalbumin (OVA-), serving as negative controls for selection, 2) were incubated with exogenously administered OVAp, modeling ubiquitous self-antigens, or 3) were generated from transgenic mice expressing OVA 
under control of the Aire-dependent rat insulin promoter (RIP), modeling endogenous TRAs (Figure 2A). CD8SP negative selection was assayed with OT-I TCR transgenic thymocytes, which express a TCR specific for OVAp 257-264 (SIINFEKLp) presented by H$2 K^{\mathrm{b}}$ (Hogquist et al. 1994). One advantage of the OT-I system is that altered peptide ligands (APLs) of varying affinities for the OT-I TCR been defined and expressed as model TRAs under control of the RIP (Koehli et al. 2014; Daniels et al. 2006). CD4SP deletion was assayed with OT-II TCR transgenic thymocytes, which recognize OVAp 323 339 presented by I-A ${ }^{b}$ (Barnden et al. 1998). This slice deletion assay allows us to test the impact of a naturally aged, non-irradiated thymic microenvironment on central tolerance, without potentially confounding differences in thymocyte ages. By varying the concentration and/or TCR-binding affinity of the OVAp APLs added to the slices, the impact of TCR-binding avidity on age-associated changes in negative selection efficiency can also be tested.

The middle-aged thymic environment does not support efficient negative selection of CD8SP thymocytes responding to moderate avidity self-antigens

To test whether the middle-aged thymus environment supports negative selection of CD8SP cells responding to ubiquitous self-antigens, 1MO OT-I thymocytes were introduced onto $1 \mathrm{MO}$ vs $12 \mathrm{MO}$ thymic slices incubated with varying concentrations of SIINFEKLp or OVA APLs. SIINFEKLp has a relatively high affinity for the OT-I TCR (Kd 3.7 $\pm 0.7 n M)$ compared with Q4R7p $\left(K_{d} 48 \pm 9.5 n M\right)$ and T4p $\left(K_{d} 55 \pm 10.1 \mathrm{nM}\right)$, (Daniels et al. 2006). All three peptides induced negative selection in a concentration dependent manner after $24 \mathrm{hr}$ on both $1 \mathrm{MO}$ and $12 \mathrm{MO}$ thymic slices, and negative selection efficiency correlated with the affinity for the OT-I TCR (Figure 2b). Notably, at higher peptide 
concentrations, there was negligible difference in the extent of CD8SP negative selection in $1 \mathrm{MO}$ versus $12 \mathrm{MO}$ thymus environments (Figure 2c). However, deletion on $12 \mathrm{MO}$ slices was significantly diminished at lower concentrations of SIINFEKLp and T4p, with a similar trend for Q4R7p (Figure 2c). In response to the low affinity T4p, the number of CD8SPs in $12 \mathrm{MO}$ slices pulsed with $0.1-10 \mathrm{nM} \mathrm{T4p} \mathrm{exceeded} \mathrm{that} \mathrm{of} \mathrm{the} \mathrm{no-peptide}$ control, likely indicating a switch to positive selection in the presence of low concentrations of a weak agonist in the middle-aged thymus environment. Together, these results indicate that the middle-aged thymic microenvironment becomes impaired in its ability to support efficient negative selection of CD8SP thymocytes responding to low avidity ubiquitous self-antigens.

To determine whether the middle-aged thymic environment supports negative selection of OT-I thymocytes responding to endogenous TRAs, thymic slices were generated from RIP-mOVA or RIP-OVA ${ }^{\text {hi }}$ mice, expressing membrane-bound or soluble forms of OVA, respectively (Kurts et al. 1996; Kurts et al. 1998). These model TRAs induce OT-I CD8SP negative selection in vivo (Gallegos \& Bevan 2004; Hubert et al. 2011) and in thymic slices (Lancaster et al. 2019). Thymic slices from OVA- littermates incubated with or without $10 \mu \mathrm{M}$ OVAp served as negative and positive controls for deletion, respectively. Relative to $1 \mathrm{MO}$ thymic slices, the $12 \mathrm{MO}$ thymic environment supported comparable deletion of OT-I thymocytes to RIP-mOVA. However, negative selection was significantly impaired in middle-aged thymic slices when OT-I thymocytes responded to the RIP-OVA ${ }^{\text {hi }}$ TRA (Figure $\mathbf{2 d}$ ), which is expressed at lower levels than the RIP-mOVA TRA (Lancaster et al. 2019). In addition, the $12 \mathrm{MO}$ thymic environment did not support efficient negative selection of OT-I thymocytes responding to lower affinity 
RIP-mQ4R7 and RIP-mT4 (Figure 2d). Together, these data indicate that negative selection is impaired in the middle-aged thymus for CD8SP thymocytes responding to TRAs with lower TCR-binding avidities, due to either low expression levels or reduced TCR-binding affinities of the selecting self-peptides.

The middle-aged thymic environment does not support efficient negative selection of CD4SP thymocytes responding to lower avidity self-antigens

To determine if the middle-aged thymus supports efficient negative selection of CD4SP thymocytes, $1 \mathrm{MO}$ OT-II thymocytes were introduced into $1 \mathrm{MO}$ versus $12 \mathrm{MO}$ thymic slices with varying concentrations of OVAp $323-339$. Slices of both ages induced concentration-dependent negative selection of OT-II CD4SPs after 24hr (Figure 3a). Notably, $12 \mathrm{MO}$ thymic slices were significantly impaired in their ability to support negative selection of OT-II thymocytes to $10 \mu \mathrm{M}$ OVAp as well as the TRAs RIP-mOVA and RIPOVA $^{\text {hi }}$ at $48 \mathrm{hr}$ (Figure $3 \mathbf{b}$ ). Thus, negative selection of CD4SP cells responsive to both ubiquitous self-antigens and TRAs is impaired in the $12 \mathrm{MO}$ thymic environment.

We also assessed whether diversion of OT-II CD4SP thymocytes towards the Treg lineage was impaired in the $12 \mathrm{MO}$ thymic environment by quantifying OT-II CD4SP $\mathrm{CD}^{+} 5^{+}$Treg precursors (Treg-P) (Hsieh et al. 2004). While the number of Treg-P generated in a middle-aged thymus did not decline significantly in response to exogenous OVAp or the RIP-mOVA TRA after 48hr of selection, the frequency of CD4SP cells upregulating CD25 was significantly diminished in response to both the ubiquitous OVAp self-antigen and the RIP-mOVA TRA (Figure $3 c$ and Supplementary Figure 2a). These findings indicate that CD4SP cells can be induced, albeit less efficiently, to divert towards a Treg fate when strong self-antigens are presented ubiquitously or as TRAs in the 
middle-aged thymus. However, in response to the less abundant RIP-OVA ${ }^{\text {hi }}$ TRA, the number OT-II CD4SP CD25+ Treg-P declined significantly in the $12 \mathrm{MO}$ thymic environment, and their frequency declined by over 3-fold (Figure 3c and Supplementary Figure 2a). Thus, diversion of autoreactive OT-II CD4SPs towards the Treg fate is particularly inefficient in response to lower avidity TRAs in the middle-aged thymic environment.

\section{Treg induction in response to TRAs is less efficient in the middle-aged thymus}

Previous studies showed that by $12 \mathrm{MO}$ of age, the mouse thymus generates very few new Treg (Thiault et al. 2015). Because we found that the $12 \mathrm{MO}$ thymic environment supports the induction of OT-II CD25+ CD4SP Treg-P in response to ubiquitous selfantigens, but not lower abundance TRAs (Figure 3), we wondered whether the ageassociated decline in de novo differentiation of Tregs preferentially impacts thymocytes responsive to a subset of self-antigens. 1 versus $12 \mathrm{MO}$ thymic slices pulsed with exogenous OVAp or expressing the RIP-mOVA or RIP-OVA ${ }^{\text {hi }}$ TRAs were tested for their ability to support OT-II CD4SP Treg differentiation after $72 \mathrm{hr}$ to enable sufficient time for FOXP3 upregulation (Weist et al. 2015). Input OT-Il thymocytes contained virtually no detectable Tregs or Treg precursors (Supplementary Figure 2b).

First we tested differentiation of $\mathrm{CD}^{2} 5^{+} \mathrm{FOXP3}^{+}$Treg and the two precursor populations, CD25 ${ }^{+}$FOXP3- $^{-}\left(\mathrm{CD}^{2} 5^{+}\right)$Treg-P and CD4 ${ }^{+}$CD25-FOXP3 ${ }^{\text {lo }}$ (FOXP3 ${ }^{\text {lo }}$ ) Treg-P (Owen et al. 2019) in response to ubiquitous self-antigens (Figure 4a). In the absence of cognate antigen (OVA- slices), OT-Il thymocytes did not differentiate into Treg-P or Tregs. In the presence of $1 \mu \mathrm{M} \mathrm{OVAp}_{323-339,}$ middle-aged slices supported generation of $\mathrm{CD}_{25} 5^{+}$ Treg-P and Treg as efficiently as young slices, although there was a slight decline in the 
frequency of Treg in $12 \mathrm{MO}$ slices (Figures $\mathbf{4 a}, \mathbf{b}, \mathbf{d}$ ). Notably, $\sim 60 \%$ of OT-II CD4SP thymocytes upregulated CD25 following addition of OVAp, regardless of the thymic microenvironment age (Figures 4a-b), indicating that access to ubiquitous antigens is not impaired in the middle-aged thymus. Exogenous OVAp did not induce many FOXP3 ${ }^{l o}$ Treg-P (Figures $4 a, c)$ ). Together, these results demonstrate that the middle-aged thymic environment efficiently supports the de novo generation of CD25+ Treg-P and Treg from thymocytes responding to ubiquitously presented self-antigens.

Next, we tested the efficiency of Treg-P differentiation in response to the Airedependent RIP-mOVA and RIP-OVA ${ }^{\text {hi }}$ TRAs in middle-aged thymic slices. 12MO slices supported $\mathrm{CD}_{2} 5^{+}$Treg-P differentiation in response to TRAs as well as $1 \mathrm{MO}$ slices, although many fewer CD25 $5^{+}$Treg- $\mathrm{P}$ were generated in response to TRAs compared to OVAp on slices of both ages (Figure 4a-b). Interestingly, in comparison to the other selfantigens, the RIP-mOVA TRA induced the highest frequency and number of FOXP3 ${ }^{10}$ Treg-P in slices of both ages (Figures 4c). Notably, the frequency of FOXP3 ${ }^{\text {lo }}$ Treg-P declined significantly in the middle-aged thymic environment for both RIP-mOVA and RIPOVA ${ }^{\text {hi }}$ TRAs, with a trend towards decreasing FOXP3 ${ }^{\text {lo }}$ Treg-P numbers (Figures 4a,c). Differentiation of CD25+ FOXP3+ Tregs in response to TRAs was the most significantly impaired in the naturally aged thymic environment. The RIP-mOVA TRA induced efficient Treg generation in $1 \mathrm{MO}$ slices, in which $\sim 25 \%$ of remaining OT-II CD4SP thymocytes at $72 \mathrm{~h}$ were Tregs. Both the number and frequency of Tregs were markedly lower in middle-aged RIP-mOVA slices, with an almost three-fold decline in frequency in the $12 \mathrm{MO}$ versus $1 \mathrm{MO}$ thymus (Figure 4d). An even more dramatic decline in Treg induction was observed in middle-aged slices expressing the less abundant RIP-OVA ${ }^{\text {hi }}$ 
TRA, in which mature Tregs were almost undetectable, representing less than $1 \%$ of the OT-II CD4SP thymocytes (Figure 4d). Together, these results demonstrate that the middle-aged thymic environment is impaired in its capacity to support Treg generation to TRAs but maintains the capacity to support Treg induction to abundant ubiquitous selfantigens.

\section{Aging associated changes in central tolerance of polyclonal thymocytes}

To determine if the decline in central tolerance we observed with antigen-specific models is also evident in polyclonal thymocytes by $12 \mathrm{MO}$ of age, we quantified negative selection and Treg induction in mice from $1 \mathrm{MO}$ to $12 \mathrm{MO}$ of age. We assessed the frequency of post-positive selection thymocyte subsets undergoing apoptosis, as identified by intracellular cleaved caspase 3 (CCasp3). CD4 ${ }^{+} \mathrm{CD} 8^{+}$double positive (DP) thymocytes were subdivided into early post-positive selection $C D 3^{\circ}{ }^{\circ} D 69^{+}$cells and later $\mathrm{CD}^{+} \mathrm{CD} 9^{+}$cells. CD4SP subsets were divided into semimature (SM), mature 1 (M1), and mature (M2) cells, and CD8SPs were subset into M1 and M2 stages based on expression of CD69 and MHC-I (Xing et al. 2016) (Figure 5a). Each subset was gated for expression of CD5 and CD3 to ensure quantification of cells that had received a TCR signal, and the frequency of Ccasp3+ cells was then quantified. In general, the less mature DP $\mathrm{CD} 3^{\circ}{ }^{\circ} \mathrm{CD} 69^{+}$cells and $\mathrm{CD} 4 \mathrm{SM}$ subsets underwent higher rates of negative selection than more mature SP subsets. Although there was a decline in the frequency of CD8SP M1 cells undergoing negative selection at $6 \mathrm{MO}$ of age, we did not observe a decline in the frequency of any polyclonal subsets undergoing negative selection by $12 \mathrm{MO}$ of age (Figure $\mathbf{5 b}$ ). Thus, overall rates of negative selection are relatively constant in the thymus from $1 \mathrm{MO}$ through $12 \mathrm{MO}$ of age, likely reflecting ongoing negative selection 
to abundant ubiquitous self-antigens, in keeping with our findings that OT-I and OT-II thymocytes were deleted fairly efficiently to high avidity ubiquitous self-antigens.

We also tested if there was a decline in the generation of polyclonal Tregs and Treg-P by $12 \mathrm{MO}$ of age (Figure 5c). Previous studies indicated that de novo Treg induction in an aging thymus is impaired due to an increased number of peripheral Treg that recirculate into the thymus where they outcompete newly differentiating Treg for limited, local IL-2, which is required for Foxp3 upregulation (Hemmers et al. 2019; Thiault et al. 2015). To quantify de novo polyclonal Treg generation with age, we distinguished newly generated from recirculating Treg based on expression of CD73 (Owen et al. 2019) (Figure 5d). The overall frequency of Treg within the CD4SP compartment diminishes significantly by $6 \mathrm{MO}$ of age and remains low at $12 \mathrm{MO}$ (Figure 5e). Within the thymic Treg compartment, the frequency of newly generated cells steadily declines over $12 \mathrm{MO}$ of age, with a concomitant increase in recirculating Treg (Figures $5 \mathbf{d}$,f), consistent with previous studies (Thiault et al. 2015). These findings indicate that the age-associated decrease in generation of new Treg can be detected in the polyclonal repertoire, consistent with our observation that Treg induction was severely compromised for OT-II thymocytes responding to TRAs and was somewhat impaired for cells responding to a ubiquitous a self-antigen in a $12 \mathrm{MO}$ thymic environment (Figure 4).

The proportion of $\mathrm{CD}^{2} 5^{+}$Treg-P within the CD4SP compartment decreases significantly with age, with a trend towards diminished frequencies of Foxp3 ${ }^{\text {lo }}$ Treg-P as well (Figure 5e). Because CD25 upregulation is induced on thymocytes encountering cognate-self antigens by TCR stimulation (Lio \& Hsieh 2008), the aging-associated reduction in $\mathrm{CD}_{2} 5^{+}$Treg-P is consistent with an age-associated decrease in thymocyte 
access to self-antigens that promote Treg differentiation. The concept that self-antigen availability limits the induction of Treg in a middle-aged thymus is concordant with the finding that OT-II thymocytes generate Treg-P fairly efficiently in a $12 \mathrm{MO}$ thymic environment in response to abundant ubiquitous self-antigens, but not to lower abundance endogenous TRAs (Figure 4).

The composition of TEC and HAPC compartments is significantly altered in a middle-aged thymus

Given the reduced capacity of the middle-aged thymus to support efficient negative selection and Treg induction, particularly against self-antigens of moderate avidities, we tested whether aging altered the cellular composition of TECs and HAPCs, the major APC subsets critical for promoting central tolerance to diverse self-antigens. TECs, B cells, pDCs, cDCs, and macrophages were quantified by flow cytometric analysis of enzymatically digested thymuses at $1,3,6$, and $12 \mathrm{MO}$ of age. cDCs were divided into cDC1 and cDC2 subsets based on expression of XCR1 and SIRP $\alpha$, respectively, while mTECs were divided from cTECs based on mTEC expression of UEA-1. Both TEC and cDC subsets were subdivided by low and high levels of MHC-II expression, and $\mathrm{CD} 80^{+} \mathrm{MHCII}^{\text {hi }}$ mTECs were further subdivided based on expression of AIRE (representative TEC and HAPC gating in Supplementary Figure 3). The number of TEC $^{\text {lo }}$ cells steadily increased from $1 \mathrm{MO}$ to $6 \mathrm{MO}$, with a slight reduction in $\mathrm{cTEC}^{\text {hi }}$ numbers by middle age (Figure 6a). Increased TEC lo numbers were reflected in their increased representation within the overall cTEC population, with a commensurate decrease in CTEC $^{\text {hi }}$ frequencies by middle-age (Figure 6a). All mTEC subsets declined numerically at 6 and $12 \mathrm{MO}$ of age, consistent with the overall decline in thymus cellularity, 
but only the $\mathrm{AIRE}^{+} \mathrm{mTEC}^{\mathrm{hi}}$ subset was reduced in frequency within the mTEC compartment, while $\mathrm{mTEC}^{\text {lo }}$ cells increased proportionally (Figure 6a). Thus, we find that by middle-age thymic involution is associated with a shift in TEC composition towards TEC $^{\text {lo }}$ and mTEC $^{\text {lo }}$ subsets, with a substantial decrease in the frequency of AIRE ${ }^{+} \mathrm{mTECs}$, the TEC subset that expresses diverse TRAs.

The HAPC compartment also undergoes significant composition changes by middle-age. The number of $\mathrm{B}$ cells does not decline by $12 \mathrm{MO}$, resulting in an increased frequency of total thymocytes (Figure 6b), consistent with previous studies (Cepeda et al. 2018). There was a trend towards decreasing plasmacytoid dendritic cell (pDC) numbers and frequencies with age (Figure 6b). cDCs numbers decreased significantly by 6 and $12 \mathrm{MO}$ of age (Figure $6 \mathbf{b}$ ). The rate of $\mathrm{cDC}$ attrition corresponded to the overall decline in thymic cellularity during involution, as their frequency remained constant with age (Figure 6b). Similarly, macrophages decreased in numbers but not in frequency by middle-age (Figure 6b). Overall, broad HAPC subsets decreased at approximately the same rate as thymic involution through middle-age, with the exception of thymic B cells, which increased in frequency.

As distinct $\mathrm{CDC}$ subsets have been differentially implicated in presenting selfantigens to induce tolerance (Leventhal et al. 2016; Perry et al. 2014; Perry et al. 2018; Oh et al. 2017; Ardouin et al. 2016), age-associated changes in cDC subsets were further evaluated. Within $X C R 1^{+} \mathrm{CDC} 1 \mathrm{~s}$, the number of both $\mathrm{CDC} 1^{\text {lo }}$ and $\mathrm{CDC} 1^{\text {hi }}$ subsets decreased significantly by $12 \mathrm{MO}$ of age. Interestingly, however, the frequency of cDC $1^{\text {hi }}$ cells decreased within the $\mathrm{cDC}$ compartment, while that of $\mathrm{cDC} 1^{\text {lo }}$ cells increased with age (Figure 6c). $\mathrm{CDC}^{\text {hi }}$ cells have been implicated in acquiring self-antigens from Aire $^{+}$ 
mTECs to induce Treg selection (Perry et al. 2014). For $c D C 2$, both $c D C 2^{10}$ and $c D C 2^{\text {hi }}$ numbers decreased significantly with age (Figure 6c). However, $\mathrm{CDC} 2^{10}$ constituted an increasing proportion of total $c D C s$ with age, while frequency of $c D C 2^{\text {hi }}$ remained constant (Figure 6d). cDC2s have also been implicated in presenting Aire-dependent antigens to induce Treg selection (Leventhal et al. 2016). Thus, similar to changes in the TEC compartment, the $\mathrm{cDC}$ compartment becomes enriched for $\mathrm{MHCI}{ }^{10}$ subsets for both $\mathrm{CDC} 1$ and $\mathrm{CDC} 2$ by middle age, consistent with reduced presentation of diverse selfantigens to induce thymocyte tolerance.

\section{Discussion}

Here we identify specific defects in central tolerance that manifest in a middle-aged thymus. Following peak thymus size and $\mathrm{T}$-cell output at $1 \mathrm{MO}$ of age in mice, thymic cellularity and T-cell export progressively decline (Srinivasan et al. 2021; Chinn et al. 2012). During age-associated thymic involution, TECs become less proliferative, their numbers diminish, and their cellular composition and organization change. The number of AIRE+ mTECs and expression of TRAs decline in a 12MO, middle-aged thymic environment (Lepletier et al. 2019; Baran-Gale et al. 2020; Bredenkamp et al. 2014; Venables et al. 2019; Griffith et al. 2012; Gray et al. 2006), suggesting central tolerance to TRAs could be particularly impaired in the involuting thymus, but this possibility had not been evaluated. In this study, we used naturally aged thymic slices to separate the age of thymus from that of thymocytes to directly test if a middle-aged thymic environment retains the capacity to support central tolerance to ubiquitous self-antigens and/or TRAs. We determine that if thymocytes encounter high avidity self-antigens presented on either 
MHC-I or MHC-II molecules, negative selection is largely preserved in a middle-aged thymus. However, the $12 \mathrm{MO}$ thymic environment does not induce efficient negative selection or Treg differentiation of thymocytes signaled by lower avidity self-antigens, regardless of whether they are presented ubiquitously throughout the thymus or in the medulla as TRAs. Thus, by middle-age, the thymus is selectively impaired in its capacity to induce central tolerance to moderate avidity self-antigens.

Thymocytes must efficiently enter the medulla to scan APCs that present the diverse self-antigens, including Aire-dependent TRAs, that establish broad self-tolerance to autoantigens throughout the body. After positive selection, thymocytes upregulate the chemokine receptors CCR7 and CCR4, which promote their accumulation within the medulla where the corresponding chemokine ligands are expressed (Hu et al. 2015; Ehrlich et al. 2009; Ueno et al. 2004). Thus, we considered the possibility that as the thymus ages, and TEC organization deteriorates, thymocyte accumulation in the medulla could be compromised. However, the middle-aged thymic environment supported robust accumulation of CD4SP thymocytes in the medulla, comparable to a young thymus. Interestingly, CCL21, which is the CCR7 ligand responsible for attracting thymocytes into the medulla (Kozai et al. 2017), is expressed at higher levels in the medulla of a middleaged relative to a young thymus. Also, post-positive selection 12MO thymocytes express comparable levels of CCR4 and CCR7 to $1 \mathrm{MO}$ thymocytes. Thus, our data indicate that impaired central tolerance in the middle-aged thymus is not due to reduced entry or accumulation of single-positive thymocytes in the medulla. 
Given that thymocyte medullary residence is limited to about 5 days (McCaughtry et al. 2007), and many self-antigens are displayed in a sparse mosaic in the thymus (Sansom et al. 2014; Meredith et al. 2015; Derbinski et al. 2008; Derbinski et al. 2005; Baran-Gale et al. 2020), thymocytes need to migrate rapidly within the medulla to encounter sufficient APCs to ensure complete tolerance. We find that the velocity of CD4SP migration is significantly reduced in a middle-aged $12 \mathrm{MO}$ versus a young $1 \mathrm{MO}$ thymic environment, regardless of thymocyte age. This reduction in migratory speed induced by the $12 \mathrm{MO}$ thymic environment could limit the number of APCs encountered, diminishing the efficiency of central tolerance. Future studies are needed to determine why thymocyte velocities are reduced in a $12 \mathrm{MO}$ thymus.

Because expression of TRAs declines with age, and our data along with previous studies show that both the absolute number of AIRE+ mTECs and their frequency within the mTEC compartment are reduced (Griffith et al. 2012; Lepletier et al. 2019; BaranGale et al. 2020; Bredenkamp et al. 2014), we hypothesized that an age-associated deficiency in negative selection would be most appreciable for TRAs. Our data are somewhat consistent with this conclusion in that the middle-aged thymic environment largely supported negative selection of OT-I CD8SP thymocytes to exogenously administered ubiquitous SIINFEKLp, while the efficiency of negative selection to the RIPOVA $^{\text {hi }}$ TRA was significantly reduced by about $30 \%$. However, ubiquitous versus Airedependent tissue restricted expression of a self-antigen was not sufficient to predict whether tolerance induction would be impaired in a middle-aged thymic environment. For example, negative selection of OT-I CD8SP thymocytes to the RIP-mOVA TRA was intact 
in $12 \mathrm{MO}$ thymic slices, while negative selection of OT-II CD4SP thymocytes to ubiquitous OVAp was impaired.

A better predictor of whether negative selection is impaired in a middle-aged thymic environment is the avidity of the selecting self-antigen for the TCR, which is impacted by both the amount of self-antigen encountered by thymocytes and the TCRbinding affinity of the self-antigen. We first evaluated negative selection using altered peptide ligands for the OT-I TCR that are reported to be just below (T4), just above (Q4R7), or well above (SIINFEKL) the TCR affinity threshold for clonal deletion (Daniels et al. 2006). OT-I negative selection in the middle-aged thymus was intact in response to high concentrations of all three self-antigens but was impaired in the presence of low concentrations of both high and low affinity peptides. Moreover, only the lowest concentration of the high affinity OT-I self-antigen revealed the deficit in negative selection in the middle-aged thymus, while this deficiency was apparent at relatively higher concentrations of lower affinity self-antigens. These findings show that the middleaged thymic environment is less efficient at displaying ubiquitous self-antigens to induce negative selection, effectively raising the avidity threshold for negative selection by middle-age. The mechanisms underlying the deficit in negative selection remain to be determined, but could reflect changes in APC composition, such as the reduced frequency of $\mathrm{MHCl}{ }^{\text {hi }} \mathrm{cDCs}$.

The middle-aged thymus was also deficient in inducing negative selection against lower avidity TRAs. Negative selection of OT-I thymocytes in $12 \mathrm{MO}$ thymic environments was intact against the higher affinity RIP-mOVA TRA, but was significantly impaired 
against the lower affinity variants RIP-mQ4R7 and RIP-mT4, as well as the high affinity RIP-OVA ${ }^{\text {hi }}$ TRA, which is expressed at lower levels than RIP-mOVA (Lancaster et al. 2019; Kurts et al. 1998). Taken together, these findings further support that negative selection to lower avidity self-antigens, even when expressed as TRAs, is impaired in the middle-aged thymus. Mechanisms underlying diminished negative selection to TRAs have yet to be determined, but could reflect a combination of the lower velocity of thymocytes, as discussed above, as well as the significant reduction in both the numbers and frequencies of AIRE ${ }^{+}$mTECs that express and present TRAs (Aschenbrenner et al., 2007; Hinterberger et al., 2010; Lancaster et al., 2019) and the MHCII ${ }^{\text {hi }}$ CDC1s that have been implicated in acquiring antigens from Aire+ mTECs for display to thymocytes (Perry et al. 2014; Perry et al. 2018).

Although the decline in negative selection observed in the middle-aged thymus may seem modest, even a small number of self-reactive $\mathrm{T}$ cells in the periphery can induce autoimmunity (Bosch et al. 2017). Interestingly, when the low affinity T4p was expressed as a TRA or presented as a low-level ubiquitous self-antigen in $12 \mathrm{MO}$ thymic slices, we consistently recovered more OT-I CD8SPs than in control slices without antigen. T4p has been shown to induce negative selection at high concentrations and positive selection at lower doses (Daniels et al. 2006). Thus, by middle-age the thymus may induce positive selection of thymocytes specific for low avidity self-antigens, perhaps resulting in export of an elevated number of autoreactive $\mathrm{T}$ cells to the periphery. Importantly, OT-I CD8 T cells that escaped negative selection to such low avidity TRAs (RIP-mQ4R7 and RIP-mT4) potently induced autoimmune diabetes upon immunization with OVAp (Koehli et al. 2014). Future experiments will investigate if OT-I CD8SP that 
escape negative selection in the middle-aged thymus more potently prime such autoimmune responses. Furthermore, although we did not find evidence of impaired negative selection of polyclonal thymocytes at $12 \mathrm{MO}$ of age, the frequency of CD8SP $\mathrm{M} 1$ cells undergoing negative selection declined at $6 \mathrm{MO}$. Because negative selection in the middle-aged thymus is impaired selectively to moderate avidity self-antigens, intact negative selection to abundant high-avidity self-antigens could have masked the deficit in polyclonal cells. Altogether, these findings suggest that impaired negative selection in a middle-aged thymus could result in export of weakly autoreactive $\mathrm{T}$ cells that have the potential to induce autoimmunity, potentially contributing to the peak in new-onset autoimmunity in middle-age (Watad et al. 2017). Future studies will test this possibility.

The middle-aged thymic environment was particularly impaired in supporting generation of new Treg responsive to TRAs; however, Treg differentiated efficiently in response to ubiquitous antigens. The $12 \mathrm{MO}$ thymic environment supported efficient Treg generation against the ubiquitous self-antigen OVAp, which was surprising as previous studies suggested that new Treg development is limited by IL-2 availability, due to competition from recirculating peripheral Tregs (Weist et al. 2015; Thiault et al. 2015). However, despite the presence of more recirculating Treg in the $12 \mathrm{MO}$ thymic environment, sufficient IL-2 was present to induce robust Treg generation in the context of exogenously added OVAp. Tregs in the thymus can arise through two distinct progenitors, CD25+ Treg-P or FOXP3 ${ }^{\text {lo }}$ Treg-P (Owen et al. 2019). In a two-step process, thymocytes first receive a TCR signal that upregulates the high-affinity IL-2 receptor $\alpha$ chain (CD25), generating CD25 ${ }^{+}$Treg-P progenitors. Subsequent IL-2 signaling induces Foxp3 expression and Treg differentiation (Lio \& Hsieh 2008; Burchill et al. 2008). 
Alternatively, thymic Tregs can arise via FoxP3 ${ }^{l o}$ Treg-P , which differ from CD25+ Treg$P$ in their transcriptome, TCR repertoire, developmental kinetics, susceptibility to apoptosis, dependence on cytokines, and suppressive functions (Tai et al. 2013; Owen et al. 2019). Exogenous OVAp induced robust CD25 expression in $1 \mathrm{MO}$ and $12 \mathrm{MO}$ thymi, indicating that the middle-aged thymus can efficiently present ubiquitous self-antigens to MHCII-restricted thymocytes. If IL-2 were limiting in the $12 \mathrm{MO}$ thymus due to an increase in recirculating Treg, fewer CD25+ Treg-P would be expected to upregulate FOXP3 and differentiate into Treg. However, the $12 \mathrm{MO}$ environment generated a comparable number of Treg as the $1 \mathrm{MO}$ environment, despite increased numbers of recirculating Treg. In contrast, there was a significant reduction in the frequency of OT-II CD4SP that differentiated into FOXP3 ${ }^{10}$ Treg-P in the $12 \mathrm{MO}$ thymic environment in response to RIPmOVA and RIP-OVA ${ }^{\text {hi }}$ TRAs. Interestingly, the RIP-mOVA TRA induced the most robust differentiation of Foxp3 ${ }^{10}$ Treg-P, with $\sim 17 \%$ of CD4SPs exhibiting this phenotype in the $1 \mathrm{MO}$ environment. Notably, the number and frequency of OT-II Tregs decline substantially in response to both model TRAs; mature Treg induction to RIP-OVA ${ }^{\text {hi }}$ in the middle-aged thymus environment was virtually extinguished. Altogether, these findings, in combination with the robust Treg generated in response to ubiquitous OVAp, are more consistent with a model in which the middle-aged thymus has a deficiency in the Treg niche that presents TRAs to CD4SP thymocytes. However, access to other cytokines that can contribute to Treg differentiation, like IL-4(Owen et al. 2019), or local concentrations of IL-2 could also be limiting. The reduced frequencies of both $\mathrm{AIRE}^{+}$ mTECs and $\mathrm{MHCII}^{\text {hi }} \mathrm{cDC} 1 \mathrm{~s}$ in the middle-aged thymic environment, both of which express and/or present Aire-dependent TRAs to autoreactive thymocytes (Perry et al. 
2014; Perry et al. 2018; Lancaster et al. 2019; Ardouin et al. 2016; Hinterberger et al. 2010; Aschenbrenner et al. 2007; Hubert et al. 2011; Gallegos \& Bevan 2004), suggest that an altered APC compartment is a major contributor to the reduction in selection of new Tregs in the aging thymic environment. However, it remains to be resolved how ageassociated changes in APC subsets impact negative selection and Treg induction to distinct self-antigens in the young versus aged thymus.

\section{Experimental Procedures}

Mice

C57BL/6J (Jackson Laboratories and NIH/NIA), B6.SJL-Ptprc ${ }^{a} P e p c^{\mathrm{b}} / \mathrm{BoyJ}$ (CD45.1), C57BL/6-Tg(TcraTcrb)1100Mjb/J (OT-I)(Hogquist et al. 1994), B6.Cg$\operatorname{Tg}$ (TcraTcrb)425Cbn/J (OT-II)(Barnden et al. 1998), C57BL/6-Tg(Ins2TFRC/OVA)296Wehi/WehiJ (RIP-mOVA)(Kurts et al. 1996), RIP-OVA ${ }^{\text {hi }}$ (W. R. Heath, University of Melbourne, Melbourne, Australia)(Kurts et al. 1998), RIP-mT4 (E. Palmer, University of Basel, Basel, Switzerland), RIP-mQ4R7 (E. Palmer, University of Basel, Basel, Switzerland) and pCX-EGFP (I. Weissman, Stanford University, Stanford, CA)(Wright et al. 2001) strains were bred in-house. All strains were sourced from Jackson Laboratories, except as specified. Mouse maintenance and experimental procedures were carried out with approval from the Institutional Animal Care and Use Committee at the University of Texas at Austin. All strains were bred and maintained under specific pathogen-free conditions in the University of Texas at Austin animal facility.

\section{Antibodies}


Antibodies used in flow cytometry and immunofluorescence analyses are detailed in Table 1. For flow cytometry, $5-10 \times 10^{6}$ cells were immunostained in $100 \mu \mathrm{L}$ of PBS + $2 \%$ bovine calf serum (BCS) with fluorochrome-conjugated antibodies. Unless otherwise specified, cells were incubated with fluorochrome-conjugated antibodies for 20 min on ice, washed twice in PBS + 2\% BCS, incubated with streptavidin for 20' on ice, washed and resuspended in $10 \mu \mathrm{g} \mathrm{mL}^{-1}$ propidium iodide $(\mathrm{PI})$ to determine viability.

Purification of thymocytes for live-cell microscopy

CD4SP cells were enriched by incubating $2 \times 10^{8}$ cells $\mathrm{mL}^{-1}$ with antibodies against CD8 (96 $\left.\mu \mathrm{g} \mathrm{mL}^{-1}\right)$ and CD11b, GR-1, TER-119, and CD25 (5 $\mu \mathrm{g} \mathrm{mL}^{-1}$ each) for $30 \mathrm{~min}$ on ice in PBS $+2 \%$ BCS, followed by immunomagnetic depletion using sheep anti-rat IgG magnetic DynaBeads (Life Technologies at a 2:1 cell:bead ratio. Magnetic depletion was repeated with half the number of beads to improve enrichments. Purity of isolated CD4SP was determined by flow cytometry using the following fluorochrome-conjugated antibodies: anti-CD3, -CD4, -CD8, and -CD69, followed by Streptavidin Qdot605 (Thermo Fisher Scientific, 1:800 dilution). Cells were washed and resuspended in $10 \mu \mathrm{g} \mathrm{mL}-1$ propidium iodide $(\mathrm{PI})$ to determine viability. Samples were analyzed on an LSR Fortessa flow cytometer (BD Biosciences), and data were analyzed using FlowJo (v.10, TreeStar).

For each slice, $10^{6}$ isolated cells were stained with either $2 \mu \mathrm{M}$ CMTPX CellTracker Red or $2 \mu \mathrm{M}$ Indo1AM (both from Life Technologies) for 30 min at $37^{\circ} \mathrm{C}$ in $1.5 \mathrm{~mL}$ of DRPMI medium (RPMI 1640 without L-glutamine, phenol red, and sodium bicarbonate; Cellgro) supplemented with $0.2 \mathrm{~g} \mathrm{~L}^{-1}$ sodium bicarbonate and $20 \mathrm{mM}$ HEPES. Cells were washed and incubated in $1.5 \mathrm{~mL}$ complete RPMI medium (RPMI 1640 with $2 \mathrm{mM} \mathrm{L-}$ 
glutamine, $50 \mathrm{U} \mathrm{mL}-1$ penicillin, $50 \mathrm{mg} \mathrm{mL}^{-1}$ streptomycin, and $10 \%(\mathrm{v} / \mathrm{v})$ fetal bovine serum) for 30 min to destain. Cells were washed, combined so that $10^{6}$ CellTracker Redlabeled cells and $10^{6}$ Indo1AM-labeled cells were mixed into each tube, and washed again with complete RPMI medium. Thymocytes were concentrated into $20-\mu \mathrm{L}$ complete RPMI medium and carefully pipetted onto the surface of each thymic slice before incubation at $37^{\circ} \mathrm{C} 5 \% \mathrm{CO}_{2}$ to allow migration of thymocytes into the thymic slice. To avoid color channel bias, $1 \mathrm{MO}$ and $12 \mathrm{MO}$ thymocyte fluorophores were swapped in different experiments.

\section{Thymic slice preparation}

For 2PM imaging, slices were generated from pCX-EGFP thymi. For negative selection assays, slices were generated from C57BL/6, RIP-mOVA, RIP-OVAhi, RIP-mT4, or RIP-mQ4R7 thymi. Dissected thymi were embedded in 4\% (w/v) NuSieve GTG lowmelting-temperature agarose (Lonza) in PBS at $37^{\circ} \mathrm{C}$. The solidified agarose block was sectioned into 400- $\mu$ m-thick slices using a VT 1000 S Microtome (Leica) in a bath of icecold PBS, with vibratome frequency set to $70 \mathrm{~Hz}$, speed to $0.20 \mathrm{~mm} \mathrm{~s}^{-1}$, and amplitude to $0.6 \mathrm{~mm}$. Slices were collected in DRPMI $+10 \%$ bovine calf serum on ice before transfer to $0.4-\mu \mathrm{m}$ tissue culture inserts (Millipore) in $35-\mathrm{mm}$ Petri dishes containing $1 \mathrm{~mL}$ of complete RPMI medium, with or without added peptides.

\section{Two-photon fluorescence microscopy}

After incubation for $\geq 1 \mathrm{~h}, \mathrm{pCX}-\mathrm{EGFP}$ thymic slices were transferred and secured in an imaging chamber (Harvard Apparatus) on the microscope stage. Perfusion medium, 
consisting of DRPMI supplemented with $2 \mathrm{~g} \mathrm{~L}^{-1}$ sodium bicarbonate, $5 \mathrm{mM}$ HEPES, and $1.25 \mathrm{mM}$ calcium chloride, was gravity fed to the stage inlet through a $300-\mathrm{mL}$ IV set, and circulated through the imaging chamber at a flow rate at $\sim 100 \mathrm{~mL} \mathrm{~h}^{-1}$, or $\sim 1$ drop per second. The perfusion medium was aerated with $95 \%$ oxygen and $5 \%$ carbon dioxide and maintained at $37^{\circ} \mathrm{C}$ with a heated microscope stage and inline perfusion heater. Images were acquired every $15 \mathrm{~s}$, through a depth of $40 \mu \mathrm{m}$, at $5-\mu \mathrm{m}$ intervals for durations of 15 min, using an Ultima IV microscope (Bruker) with a 20× water immersion objective (NA 1.0) and PrairieView software (v.5.4, Bruker). The sample was illuminated with two MaiTai titanium:sapphire lasers (Newport) tuned to $750 \mathrm{~nm}$ (for Indo1AM) and $900 \mathrm{~nm}$ (for CMTPX and EGFP). Emitted light was passed through 473/24, 525/50, and 605/70 band-pass filters (Chroma) to separate GaAsP detectors for detection of Indo1 (blue), EGFP, and CMTPX (red) fluorescence, respectively.

Migratory paths for thymocytes were tracked, and mean cell velocity and path straightness calculated using Imaris (v9, Bitplane). The enrichment of thymocytes in the medulla was determined at the first time point for each dataset by measuring the number of thymocytes in manually demarcated cortical and medullary regions.

Negative selection assays in thymic slices

$10^{6}$ OT-I or OT-II thymocytes and $10^{6}$ CD45.1 thymocytes per slice, along with the input control, were stained in $5 \mathrm{~mL}$ of DRPMI medium supplemented with $0.2 \mathrm{~g} \mathrm{~L}^{-1}$ sodium bicarbonate and $20 \mathrm{mM}$ HEPES, with $5 \mu \mathrm{M}$ CMF2HC CellTracker Blue (Life Technologies). Cells were washed and resuspended in $5 \mathrm{~mL}$ of complete RPMI medium for 30 min to destain, and then washed twice before application onto thymic slices 
generated from C57BL/6J, RIP-mOVA, RIP-OVA hi, RIP-mT4, or RIP-mQ4R7 mice. Slices were incubated in $37^{\circ} \mathrm{C} / 5 \% \mathrm{CO}_{2}$ on tissue culture inserts in Petri dishes containing $1 \mathrm{~mL}$ of complete RPMI, with or without OVAp (OVA $257-264$ for OT-I, New England Peptide; or OVA $_{323-339}$ for OT-II, GenScript), T4p (Anaspec) or Q4R7p (GenScript) peptides for specified durations.

For analysis, slices were gently washed twice by submerging in PBS and manually disrupted to obtain single-cell suspensions. Input thymocytes and slice samples were stained with the following fluorophore-conjugated antibodies: anti-CD3, -CD4, -CD8, CD25, -TCR V $\alpha 2$, -TCR V $\beta 5$, and -CD45.1 (Table 1). Samples were washed and resuspended in $10 \mu \mathrm{g} \mathrm{mL}^{-1} \mathrm{PI}$ for viability. For Treg induction experiments, samples were stained with fluorophore-conjugated antibodies against surface markers and Zombie Red viability dye (BioLegend) as described above, and fixed and permeabilized using the FOXP3/Transcription Factor Fix Perm kit (Tonbo Biosciences) per manufacturer instructions. Intracellular FOXP3 was stained by fluorophore-conjugated antibody for 20 min on ice, washed, and resuspended in PBS. After staining, $5 \times 10^{4}$ polystyrene beads were added to the tubes for cell quantification and flow cytometric analysis was carried out. Cell subsets were quantified and normalized for variable slice entry based on the ratio of control CD45.1 $1^{+}$cells in each slice to the comparable CD45.1 $1^{+}$cells in the input sample. Triplicate slices of each condition were analyzed in each experiment. Data were normalized to the average number of cells in OVA- slices in the same experiment.

Flow-cytometric analyses of thymic stroma 
Dissected thymi were cut into small fragments and enzymatically digested in 2-mL PBS with $2.5 \mathrm{mg} / \mathrm{mL}$ Liberase (Roche) with $120 \mu \mathrm{L}$ DNase I solution [10,000 U, Roche, in $10 \mathrm{~mL} \mathrm{50 \%} \mathrm{glycerol} \mathrm{:} \mathrm{50 \%} \mathrm{DNase} \mathrm{buffer}(40 \mathrm{mM}$ Tris- $\mathrm{HCl}+100 \mathrm{mM} \mathrm{NaCl}+200 \mu \mathrm{g} \mathrm{mL}-$ ${ }^{1}$ bovine serum albumin)] for 12 min at $37^{\circ} \mathrm{C}$, gently swirling halfway through incubation. The supernatant was transferred into $35 \mathrm{~mL}$ of PBS $+2 \%$ bovine calf serum and $5 \mathrm{mM}$ EDTA at $4^{\circ} \mathrm{C}$, with digestion of the remaining tissue fragments repeated twice to completely dissociate the tissue. The cells were spun down and filtered through a $70-\mu \mathrm{m}$ nylon mesh to achieve a single-cell suspension.

For TEC analyses, cells were stained with $1 \mu \mathrm{g} \mathrm{mL}^{-1}$ biotinylated Ulex europaeus agglutinin I (UEA-1; Vector Laboratories) and the following fluorophore-conjugated antibodies: anti-CD11c, -CD45, -CD80, -EpCAM, and -I-A/I-E, and Zombie Red viability dye. Secondary staining was conducted with streptavidin conjugated Qdot 605 (1:400, Invitrogen) on ice for $20 \mathrm{~min}$, followed by washing and fixation and permeabilization with the FOXP3/Transcription Factor Fix Perm kit. Intracellular AIRE was stained by fluorophore-conjugated antibody for $30 \mathrm{~min}$ on ice, washed, and resuspended in PBS. Quantification of TEC subsets was conducted by flow cytometry.

For HAPC analyses, cells were stained with the following fluorophore-conjugated antibodies: anti-CD11b, -CD11c, -CD19, -F4/80, -I-A/I-E, -PDCA-1, -SIRP $\alpha$-XCR1. After washing, secondary staining was conducted by incubating with streptavidin-conjugated Qdot 605 (1:400, Invitrogen) on ice for 20 min. Samples were washed and resuspended in $10 \mu \mathrm{g} \mathrm{mL}-1$ PI for viability. Quantification of HAPC subsets was conducted by flow cytometry. 
Flow cytometric analyses of thymocytes

Single-cell suspensions of thymocytes were obtained by manually dissociating dissected thymi and filtering cells through $40-\mu \mathrm{m}$ cell strainers. Samples were immunostained with the following fluorophore-conjugated antibodies: anti-CD3, -CD4, CD8, -CD69, -MHC-I, -CCR4, -CCR7 for $30 \mathrm{~min}$ at $37^{\circ} \mathrm{C}$, prior to washing and resuspending the cells in $10 \mu \mathrm{g} \mathrm{mL}^{-1} \mathrm{PI}$ for viability. To quantify negative selection within the thymus, thymocytes were immunostained with the following fluorophore-conjugated antibodies and dye: anti-CD3, -CD4, -CD5, -CD8, -CD69, -MHC-I and Zombie Red Viability dye (1:1000, BioLegend) for 30 min on ice. Cells were washed, then fixed and permeabilized using the Cytofix/Cytoperm kit (BD Biosciences BDB554714) per manufacturer instructions. Intracellular cleaved caspase 3 was stained with fluorophoreconjugated anti-cleaved caspase 3 antibody for 30 min on ice, washed, and resuspended in PBS for flow acquisition. Quantification of thymocyte subsets was conducted by flow cytometry.

To analyze polyclonal Tregs, single-cell thymocyte suspension were immunostained with the following fluorophore-conjugated antibodies: anti-CD3, -CD4, CD8, -CD25, -CD44, -CD73 and Zombie Red viability dye (1:1000 dilution, BioLegend) at $4^{\circ} \mathrm{C}$, and then fixed and permeabilized using the FOXP3/Transcription Factor Fix Perm kit (Tonbo Biosciences) per manufacturer instructions. Intracellular FOXP3 was immunostained with a fluorophore-conjugated antibody for $20 \mathrm{~min}$ on ice, and cells were washed and resuspended in PBS. Quantification of thymocyte subsets was conducted by flow cytometry. 
Immunofluorescence analysis of thymic cryosections

Thymuses were embedded in Tissue-Tek OCT medium and frozen using a mixture of dry ice and isopentane. 7- $\mathrm{mm}$ cryosections were generated with CryoStar NX50 cryostat (ThermoFisher) and stored at $-80^{\circ} \mathrm{C}$. Prior to immunostaining, sections were fixed in $100 \%$ acetone at $-20^{\circ} \mathrm{C}$ for 20 minutes, washed with PBS $+0.1 \%$ Tween-20, and blocked with a solution of $10 \mathrm{mM}$ Tris $\mathrm{HCl}, 150 \mathrm{mM} \mathrm{NaCl}$ and $0.5 \%$ blocking reagent (Perkin Elmer TSA Biotin System kit component). Fc receptor blocking was carried out with a 30-min room temperature stain using $10 \mu \mathrm{g} \mathrm{mL}^{-1} \alpha-C D 16 / 32$. The sections were then incubated overnight at $4^{\circ} \mathrm{C}$ with $10 \mu \mathrm{gL}^{-1} \alpha-\mathrm{CCL} 21,5 \mu \mathrm{g} \mathrm{mL}{ }^{-1} \alpha-C D 31$-biotin, and $1.66 \mu \mathrm{g} \mathrm{mL}{ }^{-1} \alpha$-Keratin 5. Following the overnight stain, the sections were incubated for

$1 \mathrm{~h}$ at room temperature with fluorophore-conjugated secondary antibodies and streptavidin-conjugated Alexa Fluor 488 (Life Technologies, S11223). 4',6-diamidino-2phenylindole (DAPI; Life technologies) was used at $0.125 \mu \mathrm{g} \mathrm{mL} \mathrm{m}^{-1}$ in PBS to stain nuclei.

\section{Statistics}

All statistical analyses were performed using Prism (GraphPad) with the corresponding test and multiple-test corrections listed in the Figure Legends.

\section{Acknowledgements}

We thank Janko Nikolich-Zugich, Nancy Manley, Marcel van den Brink, Jarrod Dudakov, Gregory Sempowski, Laura Hale, Bonnie LaFleur, and Jen Uhrlaub for constructive feedback on experiments and manuscript preparation. This research was supported by a grant from the National Institutes of Health, P01AG052359, to L.I.R.E. and E.R.R. 


\section{Conflict of Interest Statement}

The authors have no conflicts of interest to declare.

\section{Author Contributions}

J.L., D.K.-C., and L.E. designed the experiments and wrote the manuscript; J.L., D.K.-C., J.S., and Y.L. performed experiments and analyzed data; H.S. and S.N. performed experiments; E.R. and L.E. edited the manuscript.

\section{Data Availability Statement}

The data used to support the findings of this study are included within the article. Imaging and other data that support the findings of this study are available from the corresponding author upon request. 


\section{References}

Aaltonen J, Björses P, Perheentupa J, Horelli-Kuitunen N, Palotie A, Peltonen L, Lee YS, Francis F, Henning S, Thiel C, Leharach H \& Yaspo M (1997) An autoimmune disease, APECED, caused by mutations in a novel gene featuring two PHD-type zinc-finger domains. Nat. Genet. 17, 399-403.

Anderson MS (2002) Projection of an Immunological Self Shadow Within the Thymus by the Aire Protein. Science 298, 1395-1401.

Appay V \& Sauce D (2014) Naive T cells: The crux of cellular immune aging? Exp. Gerontol. 54, 90-93.

Ardouin L, Luche H, Chelbi R, Carpentier S, Shawket A, Montanana Sanchis F, Santa Maria C, Grenot P, Alexandre Y, Grégoire C, Fries A, Vu Manh T-P, Tamoutounour S, Crozat K, Tomasello E, Jorquera A, Fossum E, Bogen B, Azukizawa H, Bajenoff M, Henri S, Dalod M \& Malissen B (2016) Broad and Largely Concordant Molecular Changes Characterize Tolerogenic and Immunogenic Dendritic Cell Maturation in Thymus and Periphery. Immunity 45, 305-318.

Aschenbrenner K, D'Cruz LM, Vollmann EH, Hinterberger M, Emmerich J, Swee LK, Rolink A \& Klein L (2007) Selection of Foxp3+ regulatory T cells specific for self antigen expressed and presented by Aire+ medullary thymic epithelial cells. Nat. Immunol. 8, 351-358.

Baran-Gale J, Morgan MD, Maio S, Dhalla F, Calvo-Asensio I, Deadman ME, Handel AE, Maynard A, Chen S, Green F, Sit RV, Neff NF, Darmanis S, Tan W, May AP, Marioni JC, Ponting CP \& Holländer GA (2020) Ageing compromises mouse thymus function and remodels epithelial cell differentiation. elife 9, e56221.

Barnden MJ, Allison J, Heath WR \& Carbone FR (1998) Defective TCR expression in transgenic mice constructed using cDNA-based alpha- and beta-chain genes under the control of heterologous regulatory elements. Immunol. Cell Biol. 76, 34-40.

Bautista JL, Cramer NT, Miller CN, Chavez J, Berrios DI, Byrnes LE, Germino J, Ntranos V, Sneddon JB, Burt TD, Gardner JM, Ye CJ, Anderson MS \& Parent AV (2021) Single-cell transcriptional profiling of human thymic stroma uncovers novel cellular heterogeneity in the thymic medulla. Nat. Commun. 12, 1096.

Bornstein C, Nevo S, Giladi A, Kadouri N, Pouzolles M, Gerbe F, David E, Machado A, Chuprin A, Tóth B, Goldberg O, Itzkovitz S, Taylor N, Jay P, Zimmermann VS, Abramson J \& Amit I (2018) Single-cell mapping of the thymic stroma identifies IL-25-producing tuft epithelial cells. Nature 559, 622-626. 
Bosch AJT, Bolinger B, Keck S, Stepanek O, Ozga AJ, Galati-Fournier V, Stein JV \& Palmer E (2017) A minimum number of autoimmune T cells to induce autoimmunity? Cell. Immunol. 316, 21-31.

Bourgeois C, Hao Z, Rajewsky K, Potocnik AJ \& Stockinger B (2008) Ablation of thymic export causes accelerated decay of naive CD4 T cells in the periphery because of activation by environmental antigen. Proc. Natl. Acad. Sci. 105, 8691-8696.

Bredenkamp N, Nowell CS \& Blackburn CC (2014) Regeneration of the aged thymus by a single transcription factor. Development 141, 1627-1637.

Brennecke P, Reyes A, Pinto S, Rattay K, Nguyen M, Küchler R, Huber W, Kyewski B \& Steinmetz LM (2015) Single-cell transcriptome analysis reveals coordinated ectopic geneexpression patterns in medullary thymic epithelial cells. Nat. Immunol. 16, 933-941.

Burchill MA, Yang J, Vang KB, Moon JJ, Chu HH, Lio C-WJ, Vegoe AL, Hsieh C-S, Jenkins MK \& Farrar MA (2008) Linked T Cell Receptor and Cytokine Signaling Govern the Development of the Regulatory T Cell Repertoire. Immunity 28, 112-121.

Cepeda S, Cantu C, Orozco S, Xiao Y, Brown Z, Semwal MK, Venables T, Anderson MS \& Griffith AV (2018) Age-Associated Decline in Thymic B Cell Expression of Aire and AireDependent Self-Antigens. Cell Rep. 22, 1276-1287.

Chinn IK, Blackburn CC, Manley NR \& Sempowski GD (2012) Changes in primary lymphoid organs with aging. Semin. Immunol. 24, 309-320.

Coder BD, Wang H, Ruan L \& Su D-M (2015) Thymic Involution Perturbs Negative Selection Leading to Autoreactive T Cells That Induce Chronic Inflammation. J. Immunol. 194, 5825-5837.

Cowan JE, McCarthy NI, Parnell SM, White AJ, Bacon A, Serge A, Irla M, Lane PJL, Jenkinson EJ, Jenkinson WE \& Anderson G (2014) Differential Requirement for CCR4 and CCR7 during the Development of Innate and Adaptive $\alpha \beta T$ Cells in the Adult Thymus. J. Immunol. 193, 1204-1212.

Daniels MA, Teixeiro E, Gill J, Hausmann B, Roubaty D, Holmberg K, Werlen G, Holländer GA, Gascoigne NRJ \& Palmer E (2006) Thymic selection threshold defined by compartmentalization of Ras/MAPK signalling. Nature 444, 724-729.

den Braber I, Mugwagwa T, Vrisekoop N, Westera L, Mögling R, Bregje de Boer A, Willems N, Schrijver EHR, Spierenburg G, Gaiser K, Mul E, Otto SA, Ruiter AFC, Ackermans MT, Miedema F, Borghans JAM, de Boer RJ \& Tesselaar K (2012) Maintenance of Peripheral Naive T Cells Is Sustained by Thymus Output in Mice but Not Humans. Immunity 36, 288-297. 
Derbinski J, Gäbler J, Brors B, Tierling S, Jonnakuty S, Hergenhahn M, Peltonen L, Walter J \& Kyewski B (2005) Promiscuous gene expression in thymic epithelial cells is regulated at multiple levels. J. Exp. Med. 202, 33-45.

Derbinski J, Pinto S, Rosch S, Hexel K \& Kyewski B (2008) Promiscuous gene expression patterns in single medullary thymic epithelial cells argue for a stochastic mechanism. Proc. Natl. Acad. Sci. 105, 657-662.

Deshpande NR, Parrish HL \& Kuhns MS (2015) Self-recognition drives the preferential accumulation of promiscuous CD4+ T-cells in aged mice. eLife 4, e05949.

DeVoss J, Hou Y, Johannes K, Lu W, Liou GI, Rinn J, Chang H, Caspi RR, Fong L \& Anderson MS (2006) Spontaneous autoimmunity prevented by thymic expression of a single selfantigen. J. Exp. Med. 203, 2727-2735.

van Dommelen SL, Rizzitelli A, Chidgey A, Boyd R, Shortman K \& Wu L (2010) Regeneration of dendritic cells in aged mice. Cell. Mol. Immunol. 7, 108-115.

Ehrlich LIR, Oh DY, Weissman IL \& Lewis RS (2009) Differential Contribution of Chemotaxis and Substrate Restriction to Segregation of Immature and Mature Thymocytes. Immunity 31, 986-998.

Elyahu Y \& Monsonego A (2021) Thymus involution sets the clock of the aging T-cell landscape: Implications for declined immunity and tissue repair. Ageing Res. Rev. 65, 101231.

Flores KG, Li J \& Hale LP (2001) B cells in epithelial and perivascular compartments of human adult thymus. Hum. Pathol. 32, 926-934.

Flores KG, Li J, Sempowski GD, Haynes BF \& Hale LP (1999) Analysis of the human thymic perivascular space during aging. J. Clin. Invest. 104, 1031-1039.

Gallegos AM \& Bevan MJ (2004) Central Tolerance to Tissue-specific Antigens Mediated by Direct and Indirect Antigen Presentation. J. Exp. Med. 200, 1039-1049.

Goronzy JJ \& Weyand CM (2019) Mechanisms underlying T cell ageing. Nat. Rev. Immunol. 19, $573-583$.

Gray DHD, Seach N, Ueno T, Milton MK, Liston A, Lew AM, Goodnow CC \& Boyd RL (2006) Developmental kinetics, turnover, and stimulatory capacity of thymic epithelial cells. Blood 108, 3777-3785.

Griffith AV, Fallahi M, Venables T \& Petrie HT (2012) Persistent degenerative changes in thymic organ function revealed by an inducible model of organ regrowth: Stromal changes in thymic aging and regeneration. Aging Cell 11, 169-177. 
Hale JS, Boursalian TE, Turk GL \& Fink PJ (2006) Thymic output in aged mice. Proc. Natl. Acad. Sci. 103, 8447-8452.

Hassler T, Urmann E, Teschner S, Federle C, Dileepan T, Schober K, Jenkins MK, Busch DH, Hinterberger M \& Klein L (2019) Inventories of naive and tolerant mouse CD4 T cell repertoires reveal a hierarchy of deleted and diverted T cell receptors. Proc. Natl. Acad. Sci. 116, 18537-18543.

Hemmers S, Schizas M, Azizi E, Dikiy S, Zhong Y, Feng Y, Altan-Bonnet G \& Rudensky AY (2019) IL-2 production by self-reactive CD4 thymocytes scales regulatory $T$ cell generation in the thymus. J. Exp. Med. 216, 2466-2478.

Hinterberger M, Aichinger M, Prazeres da Costa O, Voehringer D, Hoffmann R \& Klein L (2010) Autonomous role of medullary thymic epithelial cells in central CD4+ T cell tolerance. Nat. Immunol. 11, 512-519.

Hogquist KA, Jameson SC, Heath WR, Howard JL, Bevan MJ \& Carbone FR (1994) T cell receptor antagonist peptides induce positive selection. Cell 76, 17-27.

Hsieh C-S, Liang Y, Tyznik AJ, Self SG, Liggitt D \& Rudensky AY (2004) Recognition of the Peripheral Self by Naturally Arising CD25+ CD4+ T Cell Receptors. Immunity 21, 267-277.

Hu Z, Lancaster JN, Sasiponganan C \& Ehrlich LIR (2015) CCR4 promotes medullary entry and thymocyte-dendritic cell interactions required for central tolerance. J. Exp. Med. 212, 1947-1965.

Hubert F-X, Kinkel SA, Davey GM, Phipson B, Mueller SN, Liston A, Proietto Al, Cannon PZF, Forehan S, Smyth GK, Wu L, Goodnow CC, Carbone FR, Scott HS \& Heath WR (2011) Aire regulates the transfer of antigen from $\mathrm{mTECs}$ to dendritic cells for induction of thymic tolerance. Blood 118, 2462-2472.

Ito R, Hale LP, Geyer SM, Li J, Sornborger A, Kajimura J, Kusunoki Y, Yoshida K, van den Brink MRM, Kyoizumi S, Manley NR, Nakachi K \& Sempowski GD (2017) Late Effects of Exposure to lonizing Radiation and Age on Human Thymus Morphology and Function. Radiat. Res. 187, 589.

Kadakia T, Tai X, Kruhlak M, Wisniewski J, Hwang I-Y, Roy S, Guinter TI, Alag A, Kehrl JH, Zhuang $Y$ \& Singer A (2019) E-protein-regulated expression of CXCR4 adheres preselection thymocytes to the thymic cortex. J. Exp. Med. 216, 1749-1761.

Ki S, Park D, Selden HJ, Seita J, Chung H, Kim J, Iyer VR \& Ehrlich LIR (2014) Global Transcriptional Profiling Reveals Distinct Functions of Thymic Stromal Subsets and AgeRelated Changes during Thymic Involution. Cell Rep. 9, 402-415.

Klein L, Kyewski B, Allen PM \& Hogquist KA (2014) Positive and negative selection of the T cell repertoire: what thymocytes see (and don't see). Nat. Rev. Immunol. 14, 377-391. 
Klein L, Robey EA \& Hsieh C-S (2019) Central CD4+ T cell tolerance: deletion versus regulatory T cell differentiation. Nat. Rev. Immunol. 19, 7-18.

Koehli S, Naeher D, Galati-Fournier V, Zehn D \& Palmer E (2014) Optimal T-cell receptor affinity for inducing autoimmunity. Proc. Natl. Acad. Sci. 111, 17248-17253.

Kozai M, Kubo Y, Katakai T, Kondo H, Kiyonari H, Schaeuble K, Luther SA, Ishimaru N, Ohigashi I \& Takahama Y (2017) Essential role of CCL21 in establishment of central self-tolerance in T cells. J. Exp. Med. 214, 1925-1935.

Kurobe H, Liu C, Ueno T, Saito F, Ohigashi I, Seach N, Arakaki R, Hayashi Y, Kitagawa T, Lipp M, Boyd RL \& Takahama Y (2006) CCR7-Dependent Cortex-to-Medulla Migration of Positively Selected Thymocytes Is Essential for Establishing Central Tolerance. Immunity 24, 165-177.

Kurts C, Heath WR, Carbone FR, Allison JP, Miller JFAP \& kosaka H (1996) Constitutive class Irestricted exogenous presentation of self antigens in vivo. J Exp Med 184, 923-930.

Kurts C, Miller JFAP, Subramaniam RM, Carbone FR \& Heath WR (1998) Major Histocompatibility Complex Class I-restricted Cross-presentation Is Biased towards High Dose Antigens and Those Released during Cellular Destruction. J. Exp. Med. 188, 409414.

Lancaster JN \& Ehrlich LIR (2017) Analysis of Thymocyte Migration, Cellular Interactions, and Activation by Multiphoton Fluorescence Microscopy of Live Thymic Slices. In G. E. Rainger \& H. M. Mcgettrick, eds. T-Cell Trafficking. Methods in Molecular Biology. New York, NY: Springer New York, pp.9-25. Available at: http://link.springer.com/10.1007/978-1-4939-6931-9_2 [Accessed July 31, 2020].

Lancaster JN, Li Y \& Ehrlich LIR (2018) Chemokine-Mediated Choreography of Thymocyte Development and Selection. Trends Immunol. 39, 86-98.

Lancaster JN, Thyagarajan HM, Srinivasan J, Li Y, Hu Z \& Ehrlich LIR (2019) Live-cell imaging reveals the relative contributions of antigen-presenting cell subsets to thymic central tolerance. Nat. Commun. 10, 2220.

Lepletier A, Hun ML, Hammett MV, Wong K, Naeem H, Hedger M, Loveland K \& Chidgey AP (2019) Interplay between Follistatin, Activin A, and BMP4 Signaling Regulates Postnatal Thymic Epithelial Progenitor Cell Differentiation during Aging. Cell Rep. 27, 38873901.e4.

Leventhal DS, Gilmore DC, Berger JM, Nishi S, Lee V, Malchow S, Kline DE, Kline J, Vander Griend DJ, Huang H, Socci ND \& Savage PA (2016) Dendritic Cells Coordinate the Development and Homeostasis of Organ-Specific Regulatory T Cells. Immunity 44, 847-859. 
Lio C-WJ \& Hsieh C-S (2008) A Two-Step Process for Thymic Regulatory T Cell Development. Immunity 28, 100-111.

Lynch HE, Goldberg GL, Chidgey A, Van den Brink MRM, Boyd R \& Sempowski GD (2009) Thymic involution and immune reconstitution. Trends Immunol. 30, 366-373.

Malhotra D, Linehan JL, Dileepan T, Lee YJ, Purtha WE, Lu JV, Nelson RW, Fife BT, Orr HT, Anderson MS, Hogquist KA \& Jenkins MK (2016) Tolerance is established in polyclonal CD4+ T cells by distinct mechanisms, according to self-peptide expression patterns. Nat. Immunol. 17, 187-195.

McCaughtry TM, Wilken MS \& Hogquist KA (2007) Thymic emigration revisited. J. Exp. Med. 204, 2513-2520.

Meredith M, Zemmour D, Mathis D \& Benoist C (2015) Aire controls gene expression in the thymic epithelium with ordered stochasticity. Nat. Immunol. 16, 942-949.

Mitchell WA, Lang PO \& Aspinall R (2010) Tracing thymic output in older individuals: Thymic output and age. Clin. Exp. Immunol. 161, 497-503.

Mold JE, Réu P, Olin A, Bernard S, Michaëlsson J, Rane S, Yates A, Khosravi A, Salehpour M, Possnert G, Brodin P \& Frisén J (2019) Cell generation dynamics underlying naive T-cell homeostasis in adult humans A. Bhandoola, ed. PLOS Biol. 17, e3000383.

Nagamine K, Peterson P, Scott HS, Kudoh J, Minoshima S, Heino M, Krohn KJE, Lalioti MD, Mullis PE, Antonarakis SE, Kawasaki K, Asakawa S, Ito F \& Shimizu N (1997) Positional cloning of the APECED gene. Nat. Genet. 17, 393-398.

Nasi M, Troiano L, Lugli E, Pinti M, Ferraresi R, Monterastelli E, Mussi C, Salvioli G, Franceschi C \& Cossarizza A (2006) Thymic output and functionality of the IL-7/IL-7 receptor system in centenarians: implications for the neolymphogenesis at the limit of human life. Aging Cell 5, 167-175.

Nikolich-Žugich J (2008) Ageing and life-long maintenance of T-cell subsets in the face of latent persistent infections. Nat. Rev. Immunol. 8, 512-522.

Nikolich-Žugich J (2014) Aging of the T Cell Compartment in Mice and Humans: From No Naive Expectations to Foggy Memories. J. Immunol. 193, 2622-2629.

Nuñez S, Moore C, Gao B, Rogers K, Hidalgo Y, del Nido PJ, Restaino S, Naka Y, Bhagat G, Madsen JC, Bono MR \& Zorn E (2016) The human thymus perivascular space is a functional niche for viral-specific plasma cells. Sci. Immunol. 1, eaah4447.

Oh J, Wang W, Thomas R \& Su D-M (2017) Capacity of tTreg generation is not impaired in the atrophied thymus A. Bhandoola, ed. PLOS Biol. 15, e2003352. 
Owen DL, Mahmud SA, Sjaastad LE, Williams JB, Spanier JA, Simeonov DR, Ruscher R, Huang W, Proekt I, Miller CN, Hekim C, Jeschke JC, Aggarwal P, Broeckel U, LaRue RS, Henzler CM, Alegre M-L, Anderson MS, August A, Marson A, Zheng Y, Williams CB \& Farrar MA (2019) Thymic regulatory $T$ cells arise via two distinct developmental programs. Nat. Immunol. 20, 195-205.

Perry JSA, Lio C-WJ, Kau AL, Nutsch K, Yang Z, Gordon JI, Murphy KM \& Hsieh C-S (2014) Distinct Contributions of Aire and Antigen-Presenting-Cell Subsets to the Generation of SelfTolerance in the Thymus. Immunity 41, 414-426.

Perry JSA, Russler-Germain EV, Zhou YW, Purtha W, Cooper ML, Choi J, Schroeder MA, Salazar V, Egawa T, Lee B-C, Abumrad NA, Kim BS, Anderson MS, DiPersio JF \& Hsieh C-S (2018) Transfer of Cell-Surface Antigens by Scavenger Receptor CD36 Promotes Thymic Regulatory T Cell Receptor Repertoire Development and Allo-tolerance. Immunity 48, 923-936.e4.

Quinn KM, Zaloumis SG, Cukalac T, Kan W-T, Sng XYX, Mirams M, Watson KA, McCaw JM, Doherty PC, Thomas PG, Handel A \& La Gruta NL (2016) Heightened self-reactivity associated with selective survival, but not expansion, of naïve virus-specific CD8 ${ }^{+} \mathrm{T}$ cells in aged mice. Proc. Natl. Acad. Sci. 113, 1333-1338.

Rudd BD, Venturi V, Li G, Samadder P, Ertelt JM, Way SS, Davenport MP \& Nikolich-Zugich J (2011) Nonrandom attrition of the naive CD8+ T-cell pool with aging governed by T-cell receptor:pMHC interactions. Proc. Natl. Acad. Sci. 108, 13694-13699.

Sansom SN, Shikama-Dorn N, Zhanybekova S, Nusspaumer G, Macaulay IC, Deadman ME, Heger A, Ponting CP \& Holländer GA (2014) Population and single-cell genomics reveal the Aire dependency, relief from Polycomb silencing, and distribution of self-antigen expression in thymic epithelia. Genome Res. 24, 1918-1931.

Srinivasan J, Lancaster JN, Singarapu N, Hale LP, Ehrlich LIR \& Richie E (2021) Age-Related Changes in Thymic Central Tolerance. Front. Immunol. 12, 24.

Tai X, Erman B, Alag A, Mu J, Kimura M, Katz G, Guinter T, McCaughtry T, Etzensperger R, Feigenbaum L, Singer DS \& Singer A (2013) Foxp3 Transcription Factor Is Proapoptotic and Lethal to Developing Regulatory T Cells unless Counterbalanced by Cytokine Survival Signals. Immunity 38, 1116-1128.

Thiault N, Darrigues J, Adoue V, Gros M, Binet B, Perals C, Leobon B, Fazilleau N, Joffre OP, Robey EA, van Meerwijk JPM \& Romagnoli P (2015) Peripheral regulatory T lymphocytes recirculating to the thymus suppress the development of their precursors. Nat. Immunol. 16, 628-634. 
Ueno T, Saito F, Gray DHD, Kuse S, Hieshima K, Nakano H, Kakiuchi T, Lipp M, Boyd RL \& Takahama Y (2004) CCR7 Signals Are Essential for Cortex-Medulla Migration of Developing Thymocytes. J. Exp. Med. 200, 493-505.

Varas A, Sacedón R, Hernandez-López C, Jiménez E, García-Ceca J, Arias-Díaz J, Zapata AG \& Vicente A (2003) Age-dependent changes in thymic macrophages and dendritic cells: Macrophages and DCS in the Aging Thymus. Microsc. Res. Tech. 62, 501-507.

Venables T, Griffith AV, DeAraujo A \& Petrie HT (2019) Dynamic changes in epithelial cell morphology control thymic organ size during atrophy and regeneration. Nat. Commun. 10, 4402.

Watad A, Bragazzi NL, Adawi M, Amital H, Toubi E, Porat B-S \& Shoenfeld Y (2017) Autoimmunity in the Elderly: Insights from Basic Science and Clinics - A Mini-Review. Gerontology 63, 515-523.

Weist BM, Kurd N, Boussier J, Chan SW \& Robey EA (2015) Thymic regulatory T cell niche size is dictated by limiting IL-2 from antigen-bearing dendritic cells and feedback competition. Nat. Immunol. 16, 635-641.

Wright DE, Cheshier SE, Randall TD, Christensen JL \& Weissman IL (2001) Cyclophosphamide/granulocyte colony-stimulating factor causes selective mobilization of bone marrow hematopoietic stem cells into the blood after $\mathrm{M}$ phase of the cell cycle. Blood 97, 2278-2285.

Xing Y, Wang X, Jameson SC \& Hogquist KA (2016) Late stages of T cell maturation in the thymus involve NF-KB and tonic type I interferon signaling. Nat. Immunol. 17, 565-573.

Zehn D \& Bevan MJ (2006) T Cells with Low Avidity for a Tissue-Restricted Antigen Routinely Evade Central and Peripheral Tolerance and Cause Autoimmunity. Immunity 25, 261270.

\section{Supporting Information Listing}

Supplementary Figure, related to Figure 1 Supplementary Figure 2, related to Figure 3 Supplementary Figure 3, related to Figure 6 Supplementary Movie 1, related to Figure 1 Supplementary Movie 2, related to Figure 1 Supplementary Methods 
Table 1

\begin{tabular}{|c|c|c|c|c|}
\hline Cell Marker & Clone & Fluorophore & Source & $\begin{array}{l}\text { Catalog } \\
\text { Number }\end{array}$ \\
\hline CD3 & 17A2 & PECy7 & BioLegend & 100220 \\
\hline CD4 & RM4-5 & BV510 & BioLegend & 100559 \\
\hline CD8 & 53-6.7 & FITC & BioLegend & 100706 \\
\hline $\begin{array}{l}\text { CD11b } \\
\text { (Mac-1) }\end{array}$ & $\mathrm{M} 1 / 70$ & $\begin{array}{l}\text { AlexaFluor } \\
700\end{array}$ & BioLegend & 101222 \\
\hline $\begin{array}{l}\text { CD11b } \\
\text { (Mac-1) }\end{array}$ & $\mathrm{M} 1 / 70$ & Purified & BioXCell & BE0007 \\
\hline CD11c & N418 & Pacific Blue & BioLegend & 117322 \\
\hline CD16/32 & 93 & Purified & BioLegend & 101301 \\
\hline CD19 & 1D3/CD19 & PerCPCy5.5 & BioLegend & 152405 \\
\hline CD25 & PC61 & APC & BioLegend & 102012 \\
\hline CD31 & MEC13.3 & Biotinylated & BioLegend & 102503 \\
\hline CD44 & IM7 & $\begin{array}{l}\text { AlexaFluor } \\
700\end{array}$ & BioLegend & 103026 \\
\hline CD45 & 30-F11 & BV510 & BioLegend & 103138 \\
\hline CD45.1 & A20 & APC & BioLegend & 110714 \\
\hline CD69 & $\mathrm{H} 1.2 \mathrm{~F} 3$ & Biotinylated & BioLegend & 104504 \\
\hline CD73 & TY/11.8 & PECy7 & BioLegend & 127223 \\
\hline CD80 & 16-10A1 & Pacific Blue & eBioscience & $\begin{array}{l}48-0801- \\
80\end{array}$ \\
\hline
\end{tabular}




\begin{tabular}{|l|l|l|l|l|}
\hline AIRE & $5 \mathrm{H} 12$ & FITC & eBioscience & $53-5934-$ \\
& & & & 82 \\
\hline B220 & RA3.3A1/6.1 & Purified & BioXCell & BE0067 \\
\hline CCL21 & Goat & Purified & R\&D Systems & AF457 \\
\hline polyclonal & & & & \\
\hline CCR7 & 4B12 & APC & BioLegend & 120108 \\
\hline Cleaved & D3E9 & AlexaFluor & Cell Signaling & 9603 \\
\hline EpCAM & G8.8 & 488 & & 131204 \\
\hline F4/80 & BM8 & APCCy7 & BioLegend & 123118 \\
\hline FOXP3 & FJK-16S & PE & Invitrogen & $12-5773-$ \\
\hline Keratin 5 & Poly19055 & Purified & BioLegend & 905501 \\
\hline MHC-I $(\mathrm{H}-$ & AF6-88.5 & PerCPCy5.5 & BioLegend & 116516 \\
\hline Goat IgG & Polyclonal & AlexaFluor & Jackson & $705-605-$ \\
\hline
\end{tabular}




\begin{tabular}{|l|l|l|l|l|}
\hline PDCA-1 & 927 & AlexaFluor & BioLegend & 127012 \\
\hline Rabbit IgG & Polyclonal & $\begin{array}{l}\text { AlexaFluor } \\
594\end{array}$ & $\begin{array}{l}\text { Jackson } \\
\text { Immunoresearch }\end{array}$ & 152 \\
\hline $\begin{array}{l}\text { SIRP } \alpha \\
(\text { CD172 })\end{array}$ & P84 & APC & BioLegend & 144014 \\
\hline TCR V $\alpha 2$ & B20.1 & PECy7 & BioLegend & 127822 \\
\hline TCR V $\beta 5$ & MR9-4 & FITC & BioLegend & 139514 \\
\hline TER-119 & TER-119 & Purified & BioXCell & BE0183 \\
\hline XCR1 & ZET & Biotinylated & BioLegend & 148212 \\
\hline
\end{tabular}




\section{FIGURE 1}

(a)

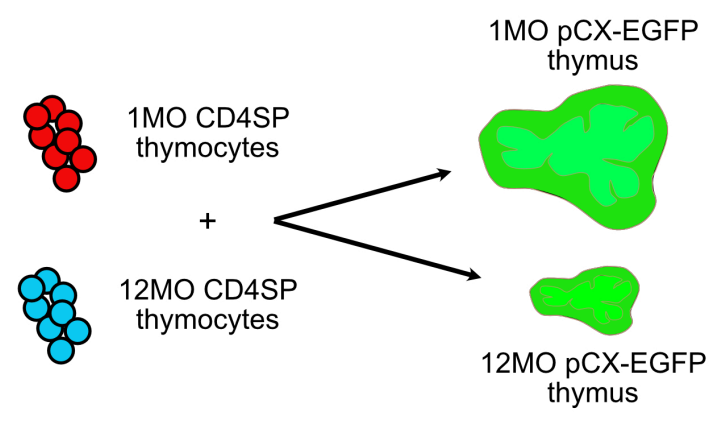

(b)
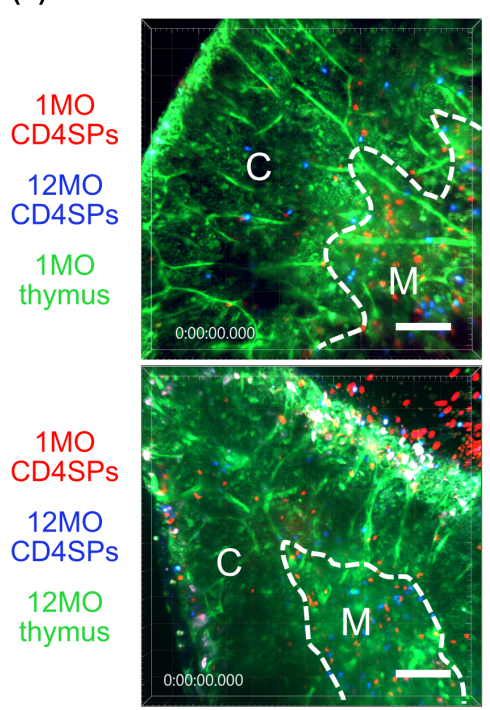

(d)
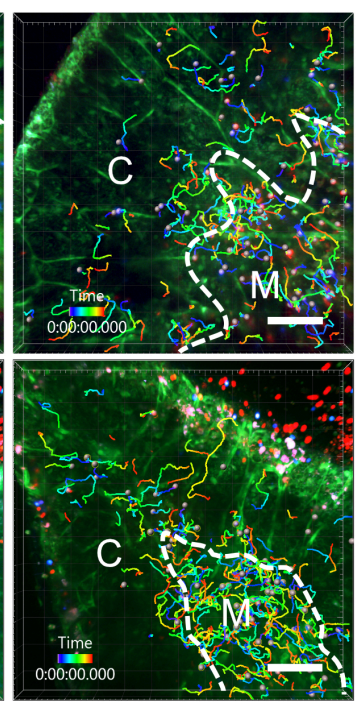

(f) live-cell 2-photon microscopy

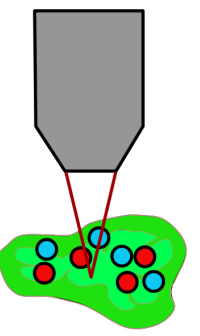

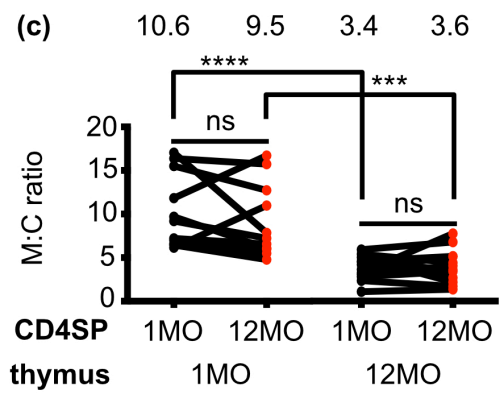

$\begin{array}{llll}11.7 & 10.3 & 13.6 & 8.3\end{array}$

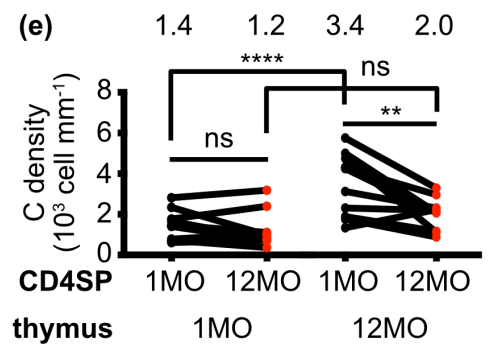

thymus

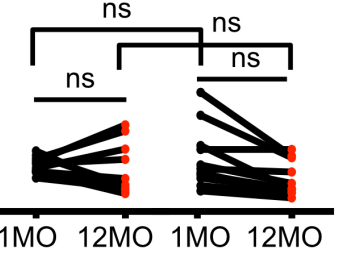

$14.0 \quad 14.5 \quad 12.0$

12.1

(g) $\quad \begin{array}{rrrr}0.46 & \begin{array}{r}0.40 \\ \mathrm{~ns}\end{array} & 0.44 & 0.45 \\ & & \end{array}$
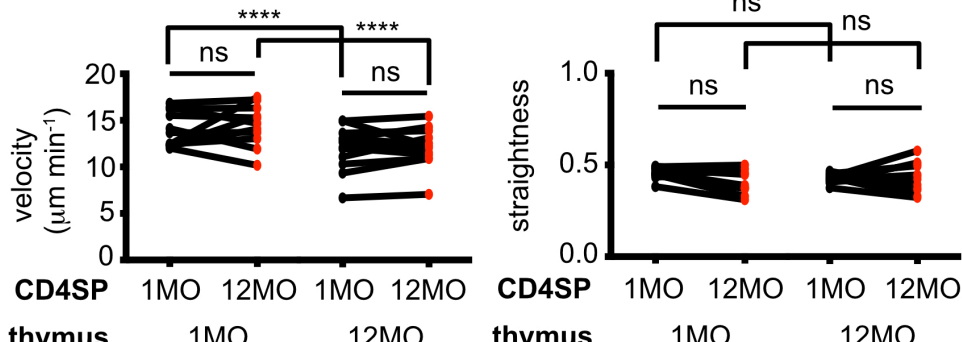
Figure 1. The middle-aged thymus environment does not support rapid motility of medullary thymocytes. (a) Schematic of 2PM approach for imaging migration of CMPTX (red)- or Indo1 AM (blue)-labeled 1MO vs $12 \mathrm{MO}$ polyclonal CD4SP thymocytes in $1 \mathrm{MO}$ or $12 \mathrm{MO}$ live pCX-EGFP (green) thymic slices. Time-lapse imaging through a $40-\mu \mathrm{m}$ depth was carried out for 15 minutes to visualize CD4SP localization and migratory properties. (b) Representative maximum intensity projections of $2 \mathrm{PM}$ imaging volumes at $20 \mathrm{X}$ magnification. The cortex $(\mathrm{C})$ and medulla $(\mathrm{M})$ are delineated by dashed white lines. $1 \mathrm{MO}$ (red) and 12MO (blue) CD4SP cells can be seen in the left images, while the right images show the same images with cell tracks color-encoded for elapsed imaging time. Scale bars, $100 \mu \mathrm{m}$. (c-e) Quantification of the density of $1 \mathrm{MO}$ and 12MO CD4SP cells in the (c) medullary versus cortical imaging volumes (M:C ratio), (d) the medulla and (e) the cortex of $1 \mathrm{MO}$ vs $12 \mathrm{MO}$ thymic slices. (f) Mean cell velocity and (g) track straightness of $1 \mathrm{MO}$ and $12 \mathrm{MO}$ thymocytes migrating within $1 \mathrm{MO}$ versus $12 \mathrm{MO}$ thymic slices. Data are compiled from 4 experiments, with each point indicating the mean thymocyte value within a given thymic slice $\left(n_{1 \mathrm{MO}}=11, n_{12 \mathrm{MO}}=12\right)$. Total cells tracked: $n_{1 \mathrm{MO}}=903$ and $n_{12 \mathrm{MO}}=$ 607 in $1 \mathrm{MO}$ slices, $n_{1 \mathrm{MO}}=1027$ and $n_{12 \mathrm{MO}}=586$ in $12 \mathrm{MO}$ slices. Analyzed by $t$-tests, $p$ values: ${ }^{* *}<0.01,{ }^{* * *}<0.001,{ }^{* * *}<0.0001$, ns: not significant. See also Supplementary Figure 1 and Movies 1 and 2. 


\section{FIGURE 2}

(a)
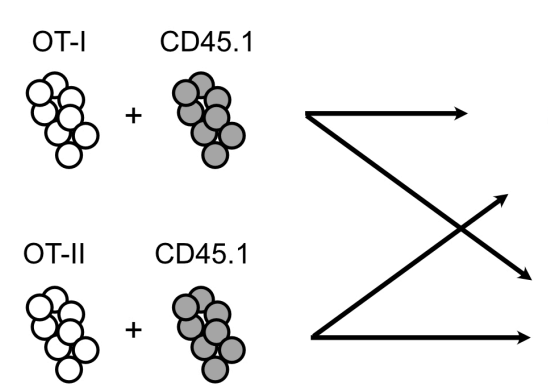

$1 \mathrm{MO}$

(b)

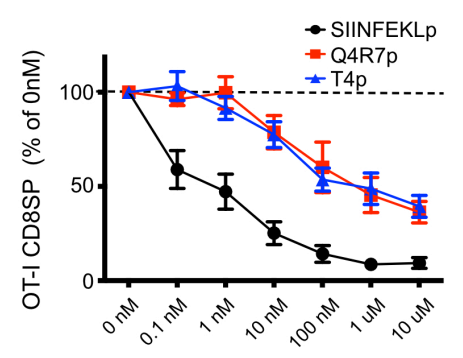

(d)

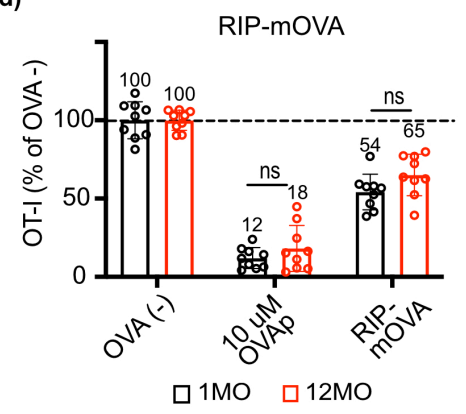

(c)
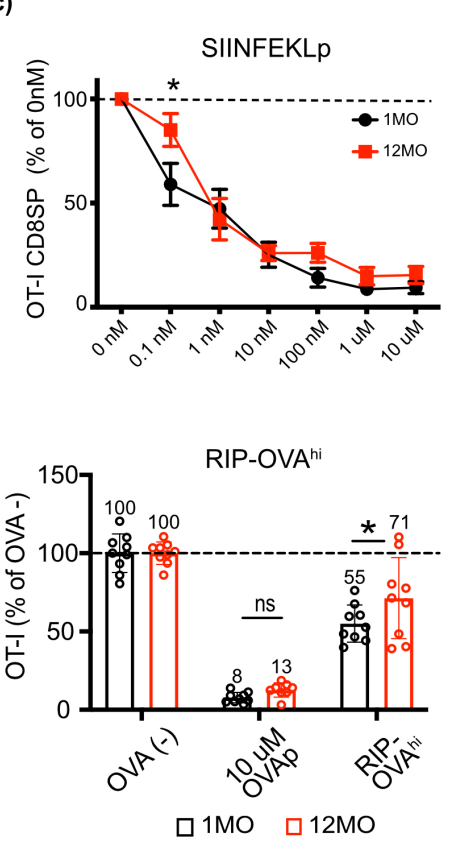

1) OVA-

2) exogenous

3) endogenous OVA TRAs or APL variants OVAp or APL

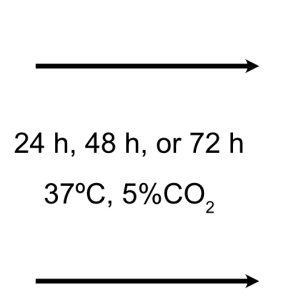

h, $48 \mathrm{~h}$, or $72 \mathrm{~h}$

$12 \mathrm{MO}$

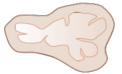

Q4R7p
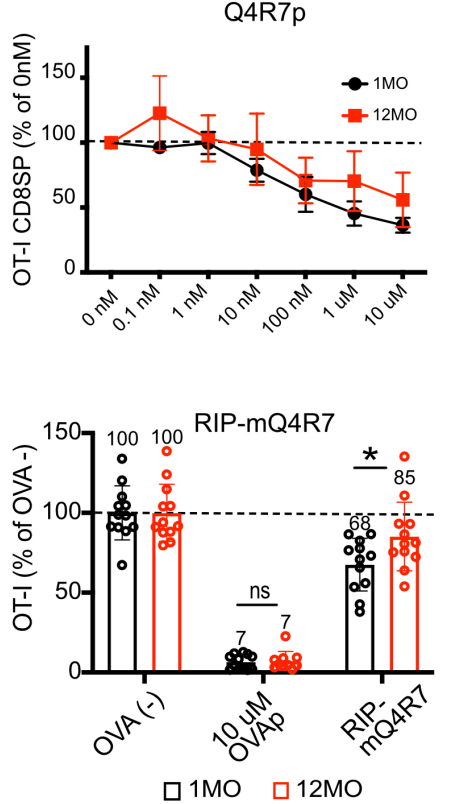

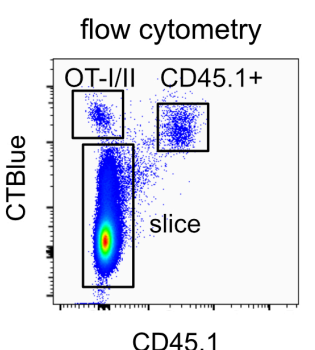

CD45.1
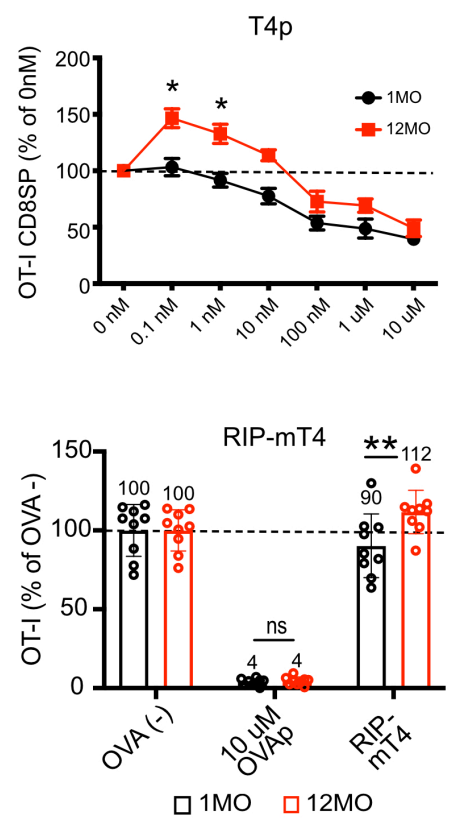
Figure 2. The $12 \mathrm{MO}$ thymic environment does not support efficient negative selection of OT-I CD8SP thymocytes responding to moderate avidity self-antigens

(a) Experimental approach of heterochronic slice deletion assays to assess negative selection of OT-I thymocytes responding to ubiquitous self-antigens or TRAs in young $(1 \mathrm{MO})$ vs middle-aged (12MO) thymic slices. Slices were generated from 1) C57BL/6J wild-type mice that did not express OVA (OVA-), 2) wild-type mice followed by incubation with OVAp or lower affinity APLs, or 3 ) the TRA strains RIP-mOVA, RIP-OVA ${ }^{\text {hi, }}$ RIPmQ4R7, or RIPmT4. (b) OT-I CD8SP cellularity in $1 \mathrm{MO}$ thymic slices incubated overnight with the indicated concentrations of SIINFEKLp, Q4R7p, or T4p, normalized to OT-I CD8SPs in slices incubated without peptide. Data compiled from 6 experiments. (c) OT-I CD8SP cellularity on $1 \mathrm{MO}$ or $12 \mathrm{MO}$ thymic slices incubated with the indicated concentrations of SIINFEKLp, Q4R7p or T4p. Data are normalized to OT-I CD8SPs in slices incubated without peptide. Data compiled from 6-7 independent experiments, with data points representing mean of triplicate thymic tissue slices. Data in (b) is a composite of the $1 \mathrm{MO}$ data shown in (c). (d) Negative selection of OT-I CD8SP thymocytes responding to AIRE-dependent TRAs in $1 \mathrm{MO}$ and $12 \mathrm{MO}$ thymic slices, evaluated at $48 \mathrm{~h}$. The proportions of OTI CD8SPs remaining in RIP-mOVA, RIP-OVA ${ }^{\text {hi }}$, RIP-mQ4R7 and RIP-mT4 thymic slices relative to the numbers in numbers in thymic slices that do not express OVA. Addition of $10 \mu \mathrm{M}$ of SIINFEKLp (OVAp) served as a positive control for OT-I negative selection. Data show mean \pm SEM compiled from 9 independent experiments, with data points representing mean of triplicate thymic tissue slices and values normalized to the mean of triplicate OVA- slices. Data in (c) and (d) were analyzed 
bioRxiv preprint doi: https://doi.org/10.1101/2022.01.17.476690; this version posted January 18,2022 . The copyright holder for this preprint (which was not certified by peer review) is the author/funder. All rights reserved. No reuse allowed without permission.

by two-way ANOVA with Šídák's correction for multiple comparisons, $p$-values: * $<0.05$, ** $<0.01$, ns: not significant. 
bioRxiv preprint doi: https://doi.org/10.1101/2022.01.17.476690; this version posted January 18,2022 . The copyright holder for this preprint (which was not certified by peer review) is the author/funder. All rights reserved. No reuse allowed without permission.

\section{FIGURE 3}

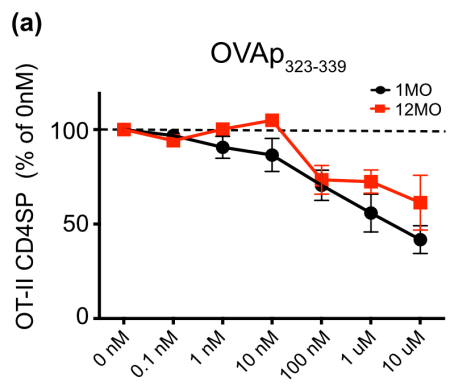

(b)

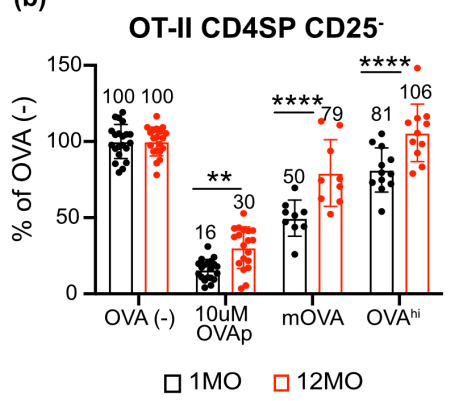

(c)

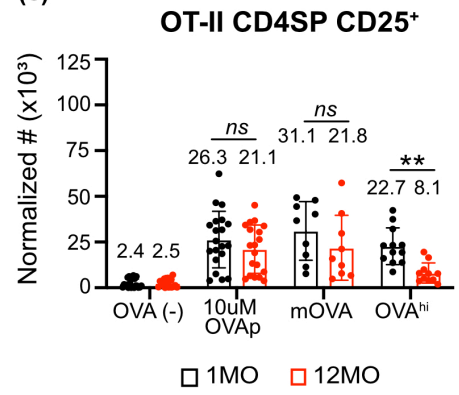

OT-II CD4SP CD25+

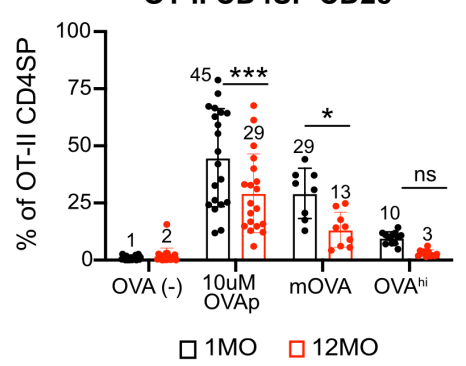


Figure 3. The middle-aged thymic environment does not support efficient negative selection of OT-II CD4SP thymocytes responding to ubiquitous self-antigens or TRAs. (a) OT-II CD4SP cellularity was quantified following incubation overnight in $1 \mathrm{MO}$ or $12 \mathrm{MO}$ thymic slices with the indicated concentrations of $\mathrm{OVAp}_{323-339}$. The frequencies of OT-II CD4SP cells remaining relative to those in slices incubated without OVAp were quantified. Plots show mean \pm SEM of compiled data from four independent experiments. Analyzed by two-way ANOVA with Šídák's correction for multiple comparisons. (b) Negative selection of CD4SP thymocytes and (c) induction of CD25+ Treg precursors to the indicated Aire-dependent TRAs on $1 \mathrm{MO}$ or $12 \mathrm{MO}$ thymic slices were quantified. Data show the relative proportions of OT-II CD4SP cells remaining in RIP-mOVA and RIPOVA $^{\text {hi }}$ thymic slices relative to thymic slices that do not express OVA. Addition of $10 \mu \mathrm{M}$ of OVAp $323-339$ (OVAp) served as a positive control for OT-II negative selection. Data in (b-c) show mean \pm SEM compiled from 4 independent experiments, with data points representing mean of triplicate thymic tissue slices. Analyzed by two-way ANOVA with Šídák's correction for multiple comparisons, $p$-values: ${ }^{*}<0.05,{ }^{* *}<0.01,{ }^{* * *}<0.001,{ }^{* * * *}$ $<0.0001$, ns: not significant. See also Supplementary Figure 2. 
bioRxiv preprint doi: https://doi.org/10.1101/2022.01.17.476690; this version posted January 18, 2022. The copyright holder for this preprint (which was not certified by peer review) is the author/funder. All rights reserved. No reuse allowed without permission.

\section{FIGURE 4}

(a)

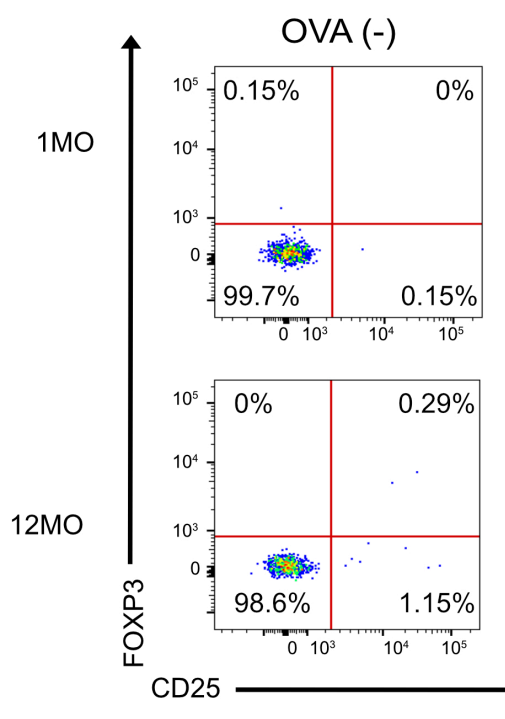

(b)
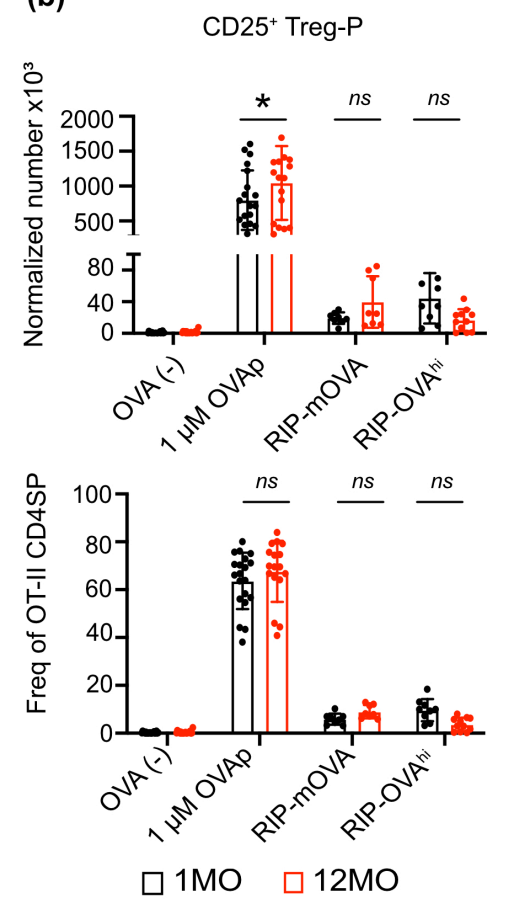
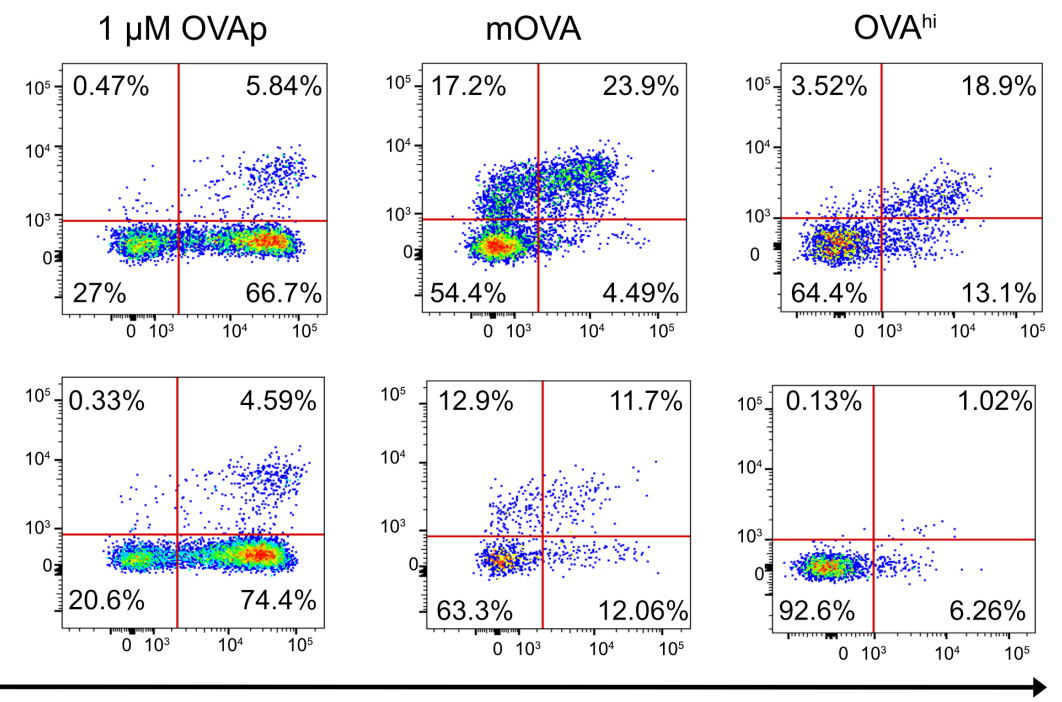

(c)

FOXP3 $3^{\text {lo }}$ Treg-P

(d)
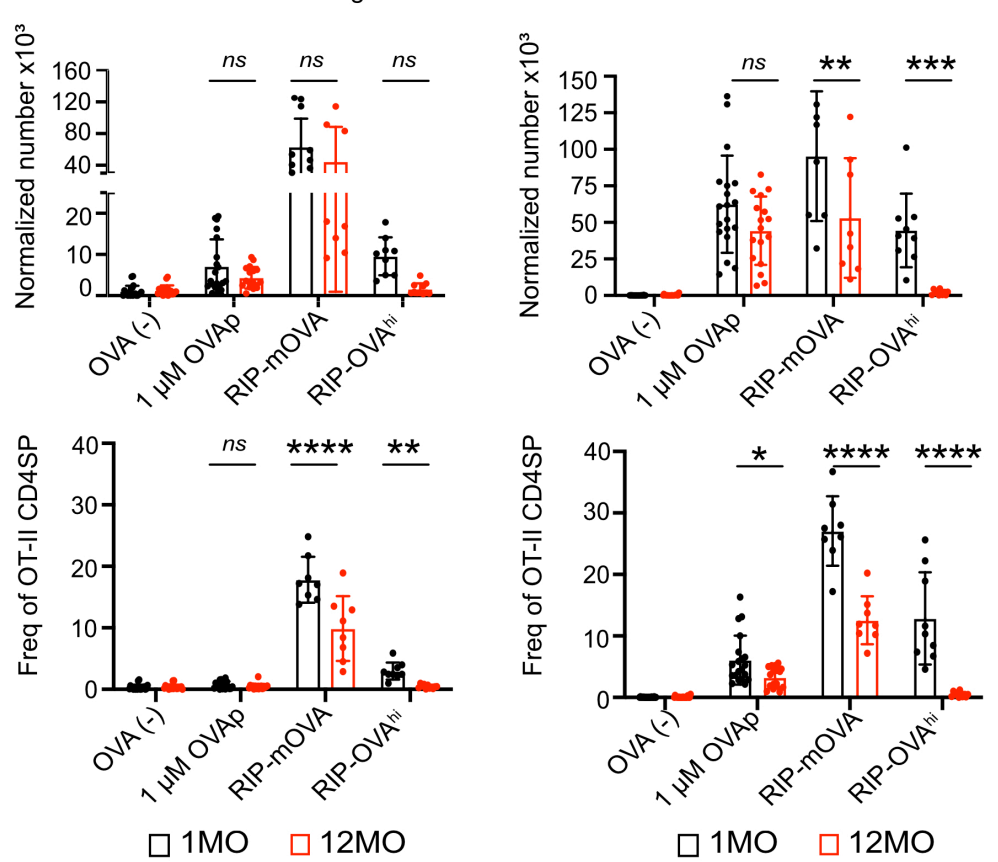
Figure 4. The middle-aged thymic environment does not support efficient induction of Tregs in response to TRAs. (a) Representative flow cytometry plots of Treg precursors $\left(\mathrm{CD} 25^{+}\right.$Treg-P and FOXP3 ${ }^{\text {lo }}$ Treg-P) and Tregs $\left(\mathrm{CD} 25^{+} \mathrm{FOXP}^{+}\right)$recovered from OVA(-), RIP-mOVA and RIP-OVA ${ }^{\text {hi }} 1 \mathrm{MO}$ versus $12 \mathrm{MO}$ live thymic tissue slices 72 hr post-incubation. Addition of $1 \mu \mathrm{M}$ of $\mathrm{OVAp}_{323-339}$ served as a positive control for Treg induction. Normalized cell numbers (top) and frequencies of OT-II CD4SP cells (bottom) of (b) CD25+ Treg-P, (c) FOXP3 ${ }^{\text {lo }}$ Treg-P and (d) Treg cells. Data in (b-d) show mean \pm SEM compiled from 3-4 independent experiments, with data points representing mean of triplicate thymic tissue slices. Analyzed by two-way ANOVA with Šídák's correction for multiple comparisons, $p$-values: ${ }^{*}<0.05,{ }^{* *}<0.01,{ }^{* * *}<0.001,{ }^{* * *}<0.0001$, ns: not significant. 
bioRxiv preprint doi: https://doi.org/10.1101/2022.01.17.476690; this version posted January 18,2022 . The copyright holder for this preprint (which was not certified by peer review) is the author/funder. All rights reserved. No reuse allowed without permission.

\section{FIGURE 5}

(a)
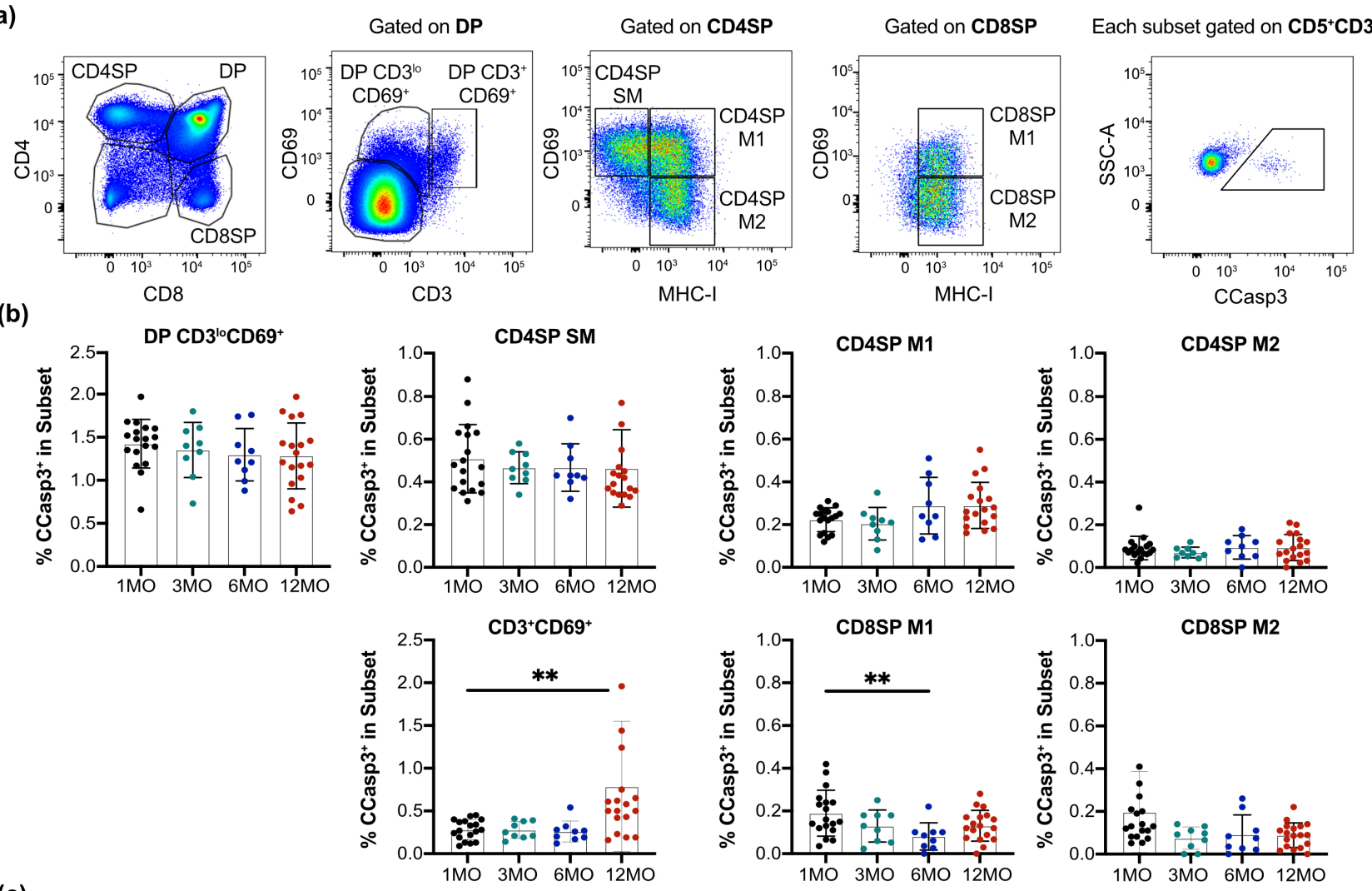

(c)
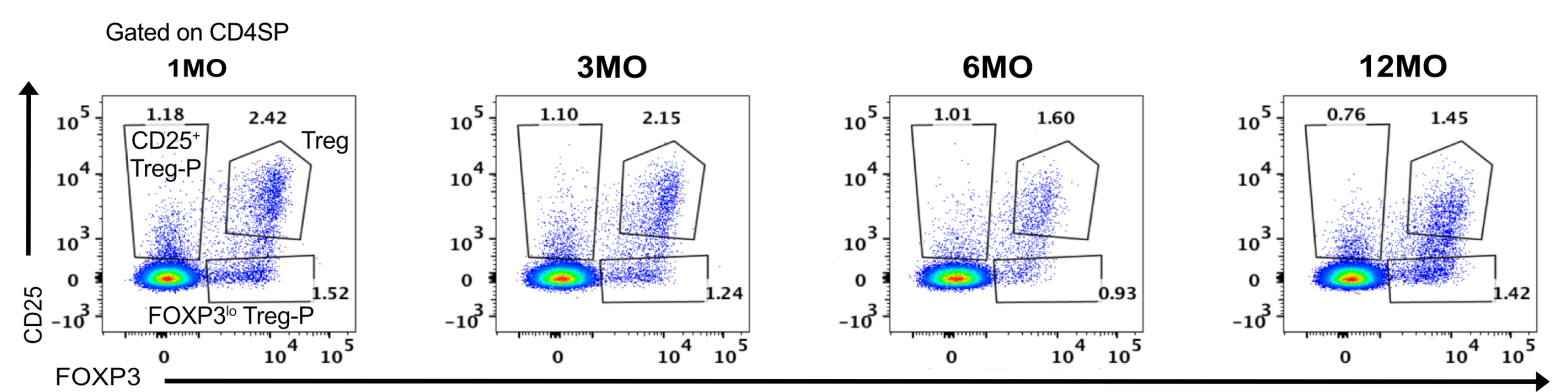

(d)
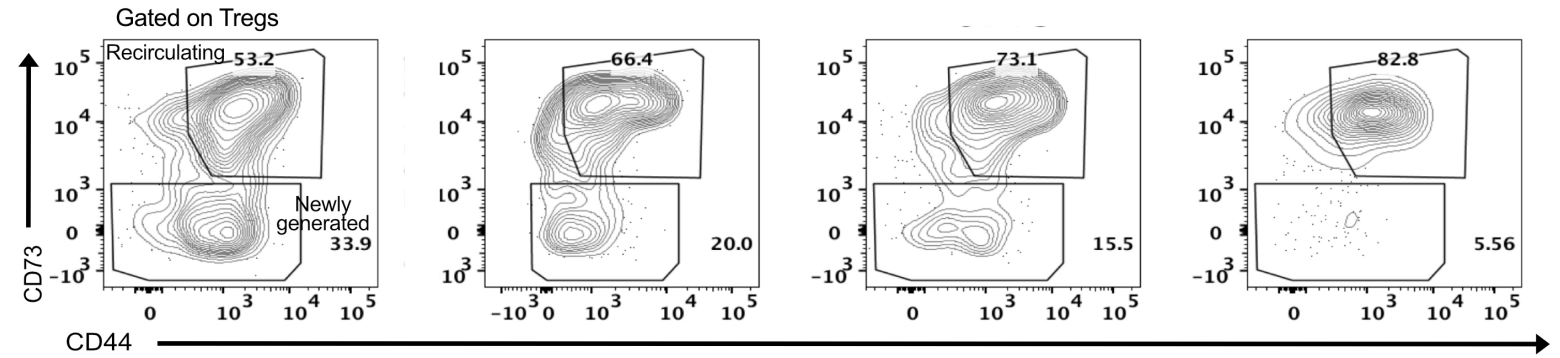

(e)

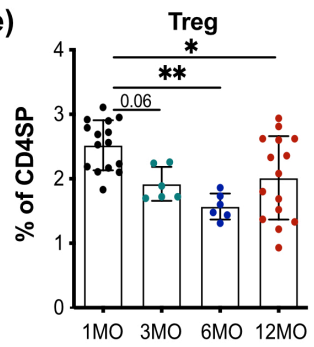

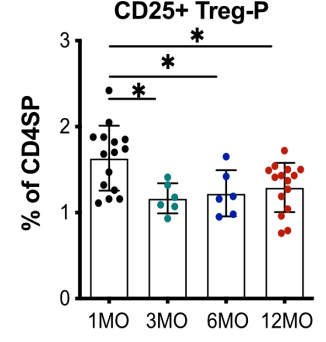

(f)

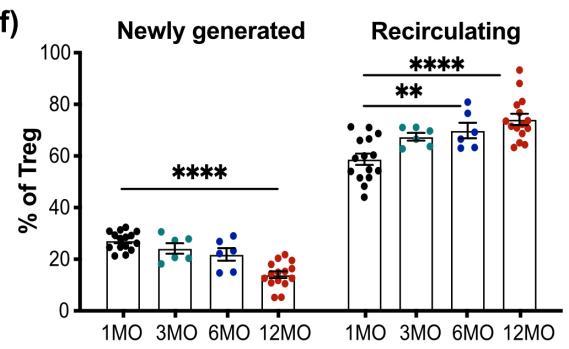


Figure 5. Aging associated changes in central tolerance of polyclonal thymocytes.

(a) Flow cytometry gating strategy for identification of thymocyte subsets undergoing negative selection in the thymus. Postpositive selection DP thymocytes were subdivided into DP $\mathrm{CD} 3^{10} \mathrm{CD} 69^{+}$and $\mathrm{DP} \mathrm{CD}^{+} \mathrm{CD}^{+} 9^{+}$stages, while CD4SP and CD8SP cells were divided into semimature (SM), mature1 (M1) and mature2 (M2) stages, as indicated. Cells were subsequently gated on $\mathrm{CD} 5^{+} \mathrm{CD}^{+}$cells to restrict analysis to thymocytes that had undergone TCR signaling, and cleaved caspase 3 (CCasp3) expression identified cells undergoing clonal deletion in each subset. (b) Quantification of the frequency of CCasp3+ cells in each thymocyte subsets from mice at 1, 3, 6 and $12 \mathrm{MO}$ of age. (c) Representative flow cytometry plots of Treg-P and Tregs at 1, 3, 6 and $12 \mathrm{MO}$ of age. (d) Representative plots of $\mathrm{CD}^{+}{ }^{+} \mathrm{CD} 25^{+} \mathrm{Foxp}^{+}$Tregs gated to distinguish newly generated (CD73-) from recirculating cells $\left(\mathrm{CD}^{+} 3^{+}\right)$in thymuses from mice at $1,3,6$ and $12 \mathrm{MO}$ of age. (e) Quantification of Tregs, CD25+ Treg-Ps, and FOXP3 ${ }^{\text {lo }}$ Treg-Ps expressed as a frequency of CD4SPs. (h) Quantification of newly generated versus recirculating Tregs expressed as a frequency of mature Tregs. (b, e-f) Plots show mean \pm SEM of nine to fifteen thymuses per age. Symbols represent individual thymuses. Analyzed by one-way ANOVA with Tukey's test for multiple comparisons, $p$-values: ${ }^{*}<0.05,{ }^{* *}<0.01,{ }^{* * *}<0.001,{ }^{* * * *}$ $<0.0001$. 


\section{FIGURE 6}

(a)

(b)

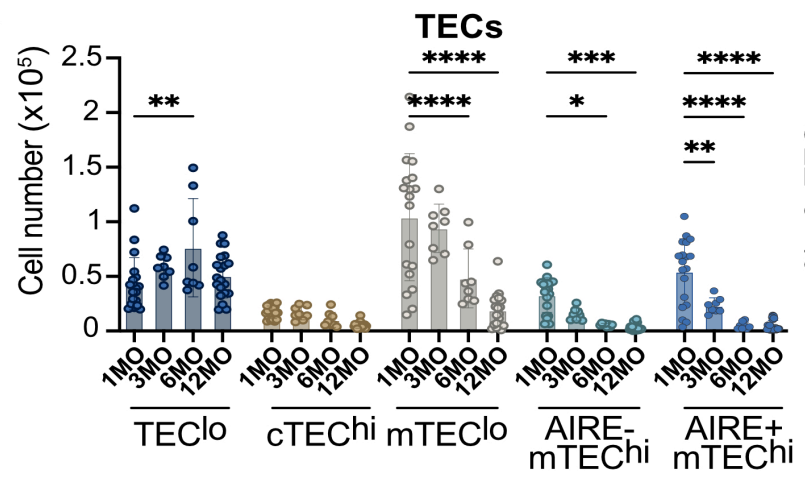

cTECs

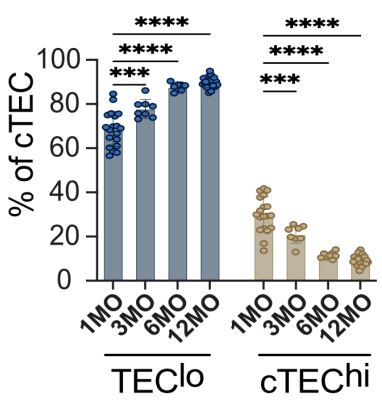

mTECs

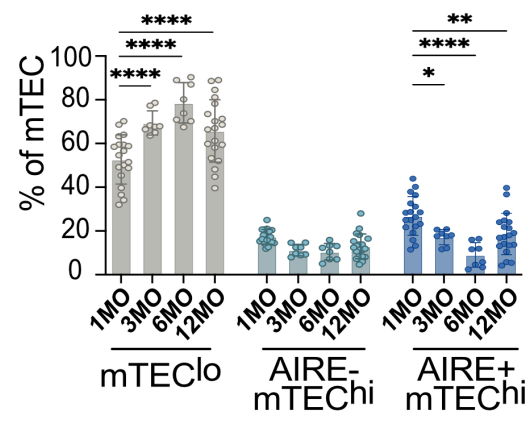

HAPC

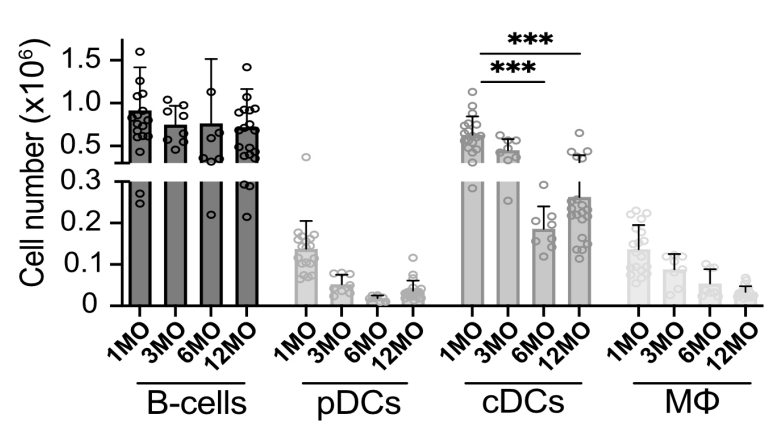

(c)

cDC subsets
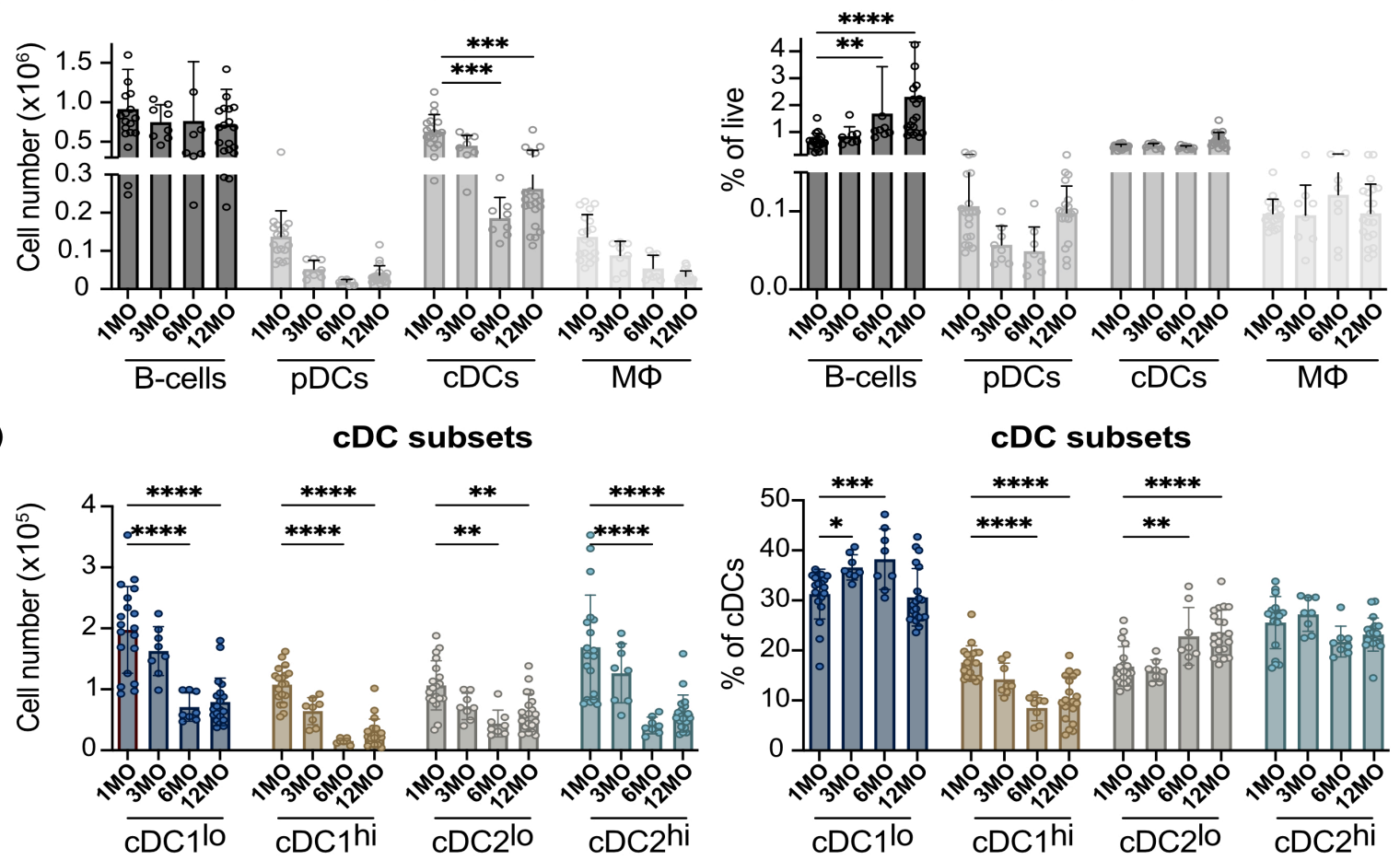
Figure 6. The composition of TEC and HAPC compartments is significantly altered in a middle-aged thymus. (a) Total cellularity and frequency of TEC subsets in 1, 3, 6 and $12 \mathrm{MO}$ thymuses were quantified by flow cytometry. (b) The total number of HAPC subsets and percent of live cells was quantified in 1, 3, 6 and $12 \mathrm{MO}$ thymus. TECs, B cells, pDC, cDCs and macrophages $(\mathrm{m} \Phi)$ were gated as shown in Supplementary Figure 3. (c) The total number of thymic cDC subsets and percentage of live cells were quantified at $1,3,6$ and $12 \mathrm{MO}$ of age. Plots show mean \pm SEM of 8-20 thymuses per age. Data are compiled from 6 experiments. Analyzed by $t$-test, $p$-values: ${ }^{*}<0.05,{ }^{* *}<0.01$, ${ }^{* * *}<0.001,{ }^{* * * *}<0.0001$ 